\title{
From Molecules to Carbon Materials-High Pressure Induced Polymerization and Bonding Mechanisms of Unsaturated Compounds
}

\author{
Xin Yang, Xuan Wang, Yida Wang, Kuo Li@ and Haiyan Zheng * \\ Center for High Pressure Science and Technology Advanced Research, Beijing 100094, China; \\ xin.yang@hpstar.ac.cn (X.Y.); xuan.wang@hpstar.ac.cn (X.W.); yida.wang@hpstar.ac.cn (Y.W.); \\ likuo@hpstar.ac.cn (K.L.) \\ * Correspondence: zhenghy@hpstar.ac.cn; Tel.: +86-10-5698-9109
}

Received: 21 August 2019; Accepted: 20 September 2019; Published: 24 September 2019

check for updates

\begin{abstract}
With the development of high-pressure apparatus, in situ characterization methods and theoretical calculations, high-pressure technology becomes a more and more important method to synthesize new compounds with unusual structures and properties. By compressing compounds containing unsaturated carbon atoms, novel poly-ionic polymers, graphanes and carbon nanothreads were obtained. Their compositions and structures were carefully studied by combining multiple cutting-edge technologies, like the in situ high-pressure X-ray and neutron diffraction, transmission electron microscopy, pair distribution function, solid-state nuclear magnetic resonance and gas chromatography-mass spectroscopy. The reaction mechanisms were investigated based on the crystal structure at the reaction threshold pressure (the pressure just before the reaction taking place), the long-range and short-range structure of the product, molecular structure of the intermediates, as well as the theoretical calculation. In this review, we will summarize the synthesis of carbon materials by compressing the unsaturated compounds and its reaction characteristics under extreme conditions. The topochemical reaction mechanism and related characterization methods of the molecular system will be highlighted. This review will provide a reference for designing chemical reaction and exploring novel carbon materials under high-pressure condition.
\end{abstract}

Keywords: high-pressure synthesis; unsaturated bonds; pressure induced polymerization; carbon materials; reaction mechanism

\section{Introduction}

Carbon is the fourth richest element in the universe after hydrogen, helium, and oxygen, which is widely studied by material scientists and organic chemists. Based on the unique bonding character, carbon can form $\mathrm{C}_{60}$, graphite, graphene, graphyne, diamond and many other polymorphs, as well as various compounds with many other elements, which form the basis of life. Among the carbon-containing compounds, those containing unsaturated carbon atoms are evidenced to polymerize and form polymers or networks under certain conditions such as with a catalyst, light, temperature and pressure.

Pressure is a key thermodynamic parameter that profoundly affects chemical reactions. Benefiting from the continuous development of high pressure and characterization technology, high -pressure science has developed rapidly in recent years and was integrated with many disciplines, promoting the development of material science, chemistry, geology and biology [1]. Under high pressure, the distances between molecules/atoms are compressed, and the electron densities and intermolecular interaction are enhanced. At a certain pressure, the system will become unstable [2]. This may induce 
chemical reactions that cannot occur at atmospheric pressure, opening new and effective ways for material design and synthesis [3]. Particularly, the molecules with unsaturated bonds can easily overcome the energy barriers and forms saturated, condensed and confined polymers with extended structures via polymerization, which is called pressure-induced polymerization (PIP). This inaugurates a new possibility to synthesize materials starting from molecular compounds. Several simple molecules that are extremely stable under ambient pressure and temperatures, such as the $\mathrm{CO}$ [4], $\mathrm{CO}_{2}$ [5], $\mathrm{N}_{2}$ [6] and $\mathrm{O}_{2}$ [7] can polymerize under high pressure. Due to the abundance of the compounds with carbon, the new carbon polymers or networks with various compositions or structures are expected. Recently, with the development of the high-pressure technology, lots of reactions of the unsaturated compounds including alkenes, alkynes, aromatics and nitriles are investigated. Especially, with the progress of in situ and ex situ characterization methods as well as the theoretical calculation, the description of the high-pressure evolution of the molecular system is far beyond phase transition. The details about the high-pressure crystal structure, the composition, bonding and the structure of the product as well as the bonding process were investigated, which promote the development of high-pressure synthesis. It becomes clear that generally, the PIP reaction undergoes a topochemical way, whereas the structure of the final product reflects the symmetry of the molecular crystal reactant or at least its relative molecular arrangement [8]. That is to say, the high-pressure chemical reaction is closely related to the crystal structure of the reactant, including the relative orientations of molecules and the intermolecular distances. Several critical distances at the pressure threshold of typical reaction were reported, which helps with understanding the PIP reaction.

In this paper, we will focus on the PIP reaction and discuss its reaction mechanism and the structure of the product. The synthesis of carbon materials including the graphanes, substituted graphanes, nanothreads and polyionic compounds by compressing the compounds with unsaturated bonds will be highlighted. The related reaction mechanisms, especially the topochemical controlled process and critical reaction distance will be reviewed. Common high-pressure apparatus and characterization techniques are also introduced. This review will not only provide some basic ideas about the unique reaction mechanisms of compounds containing unsaturated carbon atoms under high pressure but also introduce several in situ characterization techniques for high-pressure chemical studies.

\section{Generation of High Pressure and High Temperature}

Diamond anvil cell (DAC) is the most common high-pressure device. Its basic principle is to squeeze a metal gasket containing sample using two parallel diamond anvils (Figure 1a). Diamond is chosen as the anvil because of its hardness and light transmittance [9]. In addition, materials like silicon carbide, zirconia and sapphire can also be selected as anvils to avoid Raman peaks of diamonds and have better infrared transmission [10-12]. The maximum pressure limit depends on the material of anvils and the size of culets. Up to now, scientists can obtain pressure at least 550 GPa using DAC, which is equivalent to 5.5 million of atmospheres [13]. In general, the pressure in the chamber is calibrated by the fluorescence of ruby ball or chip, which red-shifts with increasing pressure. In practice, the ruby is placed into the chamber along with the sample. The laser excites the fluorescence of ruby, and the pressure in the sample chamber is determined according to the calibration equation $\mathrm{P}$ $(\mathrm{GPa})=248.4\left[\left(\lambda_{\mathrm{P}} / \lambda_{0}\right)^{7.665}-1\right][14-17]$. For the pressure higher than $100 \mathrm{GPa}$, it can be calibrated by the first-order Raman mode of diamond anvils [18] or the equation of state of standard materials by using $X$-ray diffraction. Pressure transmitting medium can reduce the temperature and pressure gradient in the chamber to obtain hydrostatic pressure. Piermarini et al. found that 4:1 methanol-ethanol solution can maintain hydrostatic pressure at room temperature up to $10.4 \mathrm{GPa}$ [19]. Ragan et al. found that silicon oil is an ideal pressure transmitting medium up to $15 \mathrm{GPa}$ [20]. For higher pressure, helium is an ideal pressure medium up to at least $50 \mathrm{GPa}$ [21]. Compared with other high-pressure devices, it is easy to load the sample into DAC and many in situ techniques can be integrated for different applications, but the sample size is small, generally about tens to hundreds of microns in diameter and thickness. 
Paris-Edinburg cell (PE cell) is a medium-sized high press device with tungsten carbide, zirconia-toughened alumina or polycrystalline sintered diamond as anvils (Figure 1b) [22,23]. The anvils normally used include single-toroidal and double-toroidal type. The typical single-toroidal anvil can accommodate up to $\sim 80 \mathrm{~mm}^{3}$ of the sample with a maximum pressure of around $10 \mathrm{GPa}$, while the double-toroid has a maximum pressure of $28 \mathrm{GPa}$ and the sample size of $10-30 \mathrm{~mm}^{3}$. Due to the large sample size and easy operation, it is often combined with high- and low-temperature technology for in situ neutron diffraction experiments. In addition, by combining with ultrasonic technology and X-ray imaging, high-speed X-ray radiography (> 1000 frames/sec) and falling sphere viscometry, it is also used to measure the elastic wave velocity and viscosity of liquid samples. This is helpful for us to study the structural and physical properties of liquid and amorphous materials under high pressure and high temperature conditions [24]. Another high-pressure generation device for high pressure synthesis is Large Volume Press (LVP), which can be divided into different types according to the number and shape of anvil $[25,26]$. Its sample volume is generally in the order of millimeters, and it has wider application in material synthesis. Moreover, it can be combined with high-temperature technology to produce high and uniform pressure up to $\sim 90 \mathrm{GPa}$ and temperature up to $3000 \mathrm{~K}$ [25]. Besides the application in synthesis, it is often combined with electrical, thermal, and crystallographic methods to study the properties or structures of complex systems.

(a)

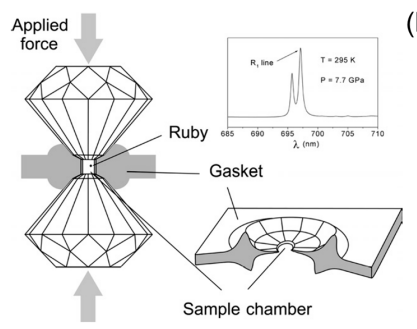

(b)

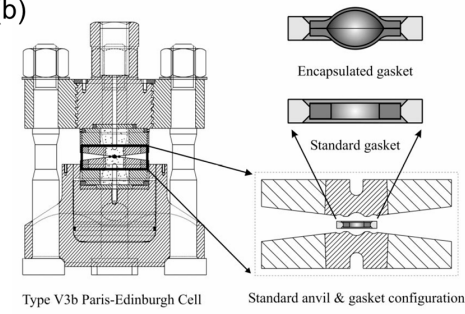

Figure 1. (a) The assembling of diamond anvil cell (DAC) and its sample chamber. A ruby chip is placed in the sample chamber for the local pressure calibration [17]. (b) The structure of PE cell with its anvil and gasket [23].

There are several ways to apply high temperature to the sample in DAC, mainly including laser and resistance heating [27]. Laser heating is achieved by focusing $\mathrm{Nd}$ : YAG or $\mathrm{CO}_{2}$ lasers on the sample $[28,29]$. The temperature is determined by measuring the thermal radiation intensity and fitting the Planck blackbody radiation equation $[30,31]$. This method is fast, and the maximum temperature is up to $6000 \mathrm{~K}$ [32]. Due to the small spot of the laser beam, there is a significant temperature gradient in the pressure chamber, which may cause inhomogeneous heating. In comparison, resistive heating often provides better homogeneity. A popular type of DAC for external heating is BX90 DAC [33]. A resistive ring heater is set around the diamond, which provides a uniform and stable high-temperature environment, and the temperature is measured by a thermocouple attached to the diamond [34]. However, due to the power density limit and heat loss, the temperature of resistive heating is typically below $1300 \mathrm{~K}$.

\section{In Situ Characterization Under High Pressure}

DAC can be easily utilized in various in situ optical characterization techniques due to the good light transmission of the diamond, like Raman and infrared (IR) spectroscopy. There are many introductions on in situ high-pressure Raman spectroscopy, which will not be described in detail here [35-37]. Using Raman spectroscopy, molecular vibration modes can be obtained conveniently in a non-destructive and non-ionizing radiation manner. However, the fluorescence of some samples significantly interferes with the Raman signals and sometimes the laser will damage the samples. IR spectroscopy can effectively avoid fluorescence interference from the sample, and act as an important complementary technique to investigate the reaction process and provide the information on reacting 
precursors or products [38]. In practice, type II diamonds, the diamonds without nitrogen aggregates, are required to avoid the absorption at $1000-1300 \mathrm{~cm}^{-1}$. The empty DAC should be measured to act as the background. If the sample absorbance is out of the range, diamond or dry $\mathrm{KBr}$ slice need to be loaded into the sample chamber to reduce the sample thickness. Besides, the in situ UV-vis absorption and photoluminescence (PL) spectroscopy can also be measured by combining with DACs [39].

For in situ electrical measurements, typically, a hole is drilled at the center of the pre-compressed metal gasket and cubic boron nitride is filled into the hole as an insulation layer. Then a smaller hole is drilled at the center of boron nitride as a sample chamber. Both manual wiring and film-fabricating technologies are used to build an integrated microcircuit on the diamond anvil [40]. Manual wiring refers to cutting platinum foil into long strips with a width of tens of micron by hand and fixing electrodes with silver glue. For the film-fabricating [41], the scientists use film deposition along with photolithographic shaping method to form a multi-layer microcircuit on a diamond surface where molybdenum is chosen as the electrode material and alumina is used for insulation (Figure 2). Utilizing in situ electrical measurements, scientists realize the measurement of resistivity [42], transport properties [43], Hall effect [44] and magnetoresistance [45].

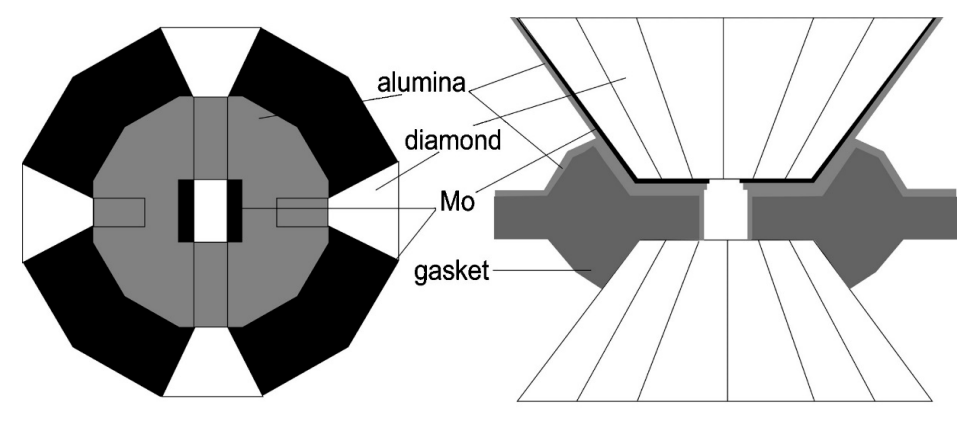

(a)

(b)

Figure 2. (a) Configuration of a microcircuit on a diamond anvil [40]. (b) Diagram of a microcircuit in a diamond anvil cell [40].

X-ray diffraction (XRD) is the most commonly used method for crystallographic characterization. For the sample of heavy elements under relatively low pressure, both single crystal XRD and powder XRD experiments can be completed in the laboratory. But for the sample with a low atomic number, especially organic compounds, the high-energy, high-brightness, quasi-focus synchrotron X-rays are needed to get good data for the structural characterization. The basic principle is that $\mathrm{X}$-rays transmit through the upstream diamond and irradiate on the sample, and then the diffracted beams emit through the downstream diamond. Additionally, a variety of synchrotron techniques such as X-ray absorption spectroscopy [46], X-ray emission spectroscopy [47], X-ray Raman spectroscopy [48], and X-ray imaging techniques can also be integrated with DAC.

Neutrons have many unique advantages, such as high penetration, strong interaction with magnetic moments, and isotopic sensitivity. Unlike X-rays, the interactions between neutron and nucleus do not increase monotonically with increasing atomic number. Therefore, neutrons are particularly suitable for distinguishing the position of light elements and the adjacent elements in crystal structures. Neutron sources that are used for high pressure experiments in the world include Spallation Neutron Source (SNS) in the United States [49], Japan Proton Accelerator Research Complex (J-Parc) in Japan [50], ISIS in the United Kingdom [51], Institute Laue-Langevin (ILL) and Swiss Spallation Neutron Source (SINQ) in Europe, and China Mianyang Research Reactor (CMRR) in China. Since neutron diffraction requires a larger volume of sample $\left(>10 \mathrm{~mm}^{3}\right)$, PE cell is often used [52]. In the neutron diffraction experiment, the majority of gaskets are machined from the null-scattering Ti-Zr alloy, composed of $67.6 \mathrm{~mol} \%$ titanium and $32.4 \mathrm{~mol} \%$ zirconium, which have negative and positive neutron scattering lengths, respectively [51]. To obtain neutron diffraction data at higher pressure, 
scientists studied many other types of cells for neutron diffraction. The gem anvil cells (GACs) were developed for neutron diffraction studies, which often use sapphire anvils. It can carry more samples than DAC, and the pressure can reach to $43 \mathrm{GPa}$ [53]. By developing a supported diamond-anvil cell (S-DAC) and coupling it with the intense radiation flux at the dedicated high-pressure diffraction instrument Spallation Neutrons and Pressure Diffractometer (SNAP) in Spallation Neutron Source (SNS), Oak Ridge National Laboratory (ORNL), Malcolm Guthrie et al. measured the neutron data of ice VII up to $94 \mathrm{GPa}$ at room temperature [54]. Utsumi et al. use nano-polycrystalline diamond (NPD) instead of single crystal diamond as the anvils. The NPD has no cleavages and potentially larger size chunks which are suitable for the anvil material [55]. By using the NPD anvils, the pressure up to $60 \mathrm{GPa}$ can be achieved with the sample volumes of $\sim 1 \mathrm{~mm}^{3}$. Another example is Kurchatov-LLB cell, which allows us to study neutron diffraction at pressures up to $50 \mathrm{GPa}$, temperatures down to $0.1 \mathrm{~K}$, and applied magnetic fields up to $7.5 \mathrm{~T}$ [56]. It uses aluminum, niobium, copper, copper-nickel, or copper-beryllium gaskets with single-crystal sapphire or diamond anvils.

\section{The Ionic Compounds with Unsaturated Bonds}

Under high pressure, unsaturated ions approach to each other against the electrostatic repulsion, which may lead to PIP. Compounds with high charge density on the skeletal and highly doped metal can be obtained. These compounds are often predicted to be superconductive materials or battery materials. The negative charge on the polymer ions will make them good nucleophiles and thus important precursors for functional materials.

\subsection{Metallic Carbide}

The metal acetylides like $\mathrm{CaC}_{2}, \mathrm{Li}_{2} \mathrm{C}_{2}, \mathrm{MgC}_{2}$ and $\mathrm{BeC}_{2}$ contain the unsaturated $\mathrm{C} \equiv \mathrm{C}^{2-}$, which is an important precursor to synthesize the carbon materials under high pressure [57]. It is predicted that under high pressure, the dumbbell acetylide anions in the $\mathrm{CaC}_{2}$ and $\mathrm{Li}_{2} \mathrm{C}_{2}$ transform to form $1 \mathrm{D}$ chain, ribbon and $2 \mathrm{D}$ graphitic sheet [58]. For $\mathrm{BeC}_{2}$ and $\mathrm{MgC}_{2}$, the poly-five-membered ring structures were predicted [59]. In the pressure-composition phase diagram of $\mathrm{Li}-\mathrm{C}$ and $\mathrm{Ca}-\mathrm{C}$ system, more complex structures were predicted, including carbon dimers, trimmers, ribbons and framework [60,61].

The main challenge for the experimental investigation is the shortage of characterization techniques. In the previous study, a lot of efforts have been made to study the high-pressure behavior of $\mathrm{CaC}_{2}$, $\mathrm{Li}_{2} \mathrm{C}_{2}$ and $\mathrm{BaC}_{2}$. Phase transition is observed in $\mathrm{Li}_{2} \mathrm{C}_{2}$ and $\mathrm{BaC}_{2}$ at $15 \mathrm{GPa}$ and $4 \mathrm{GPa}$, respectively. When the pressure is up to $25 \mathrm{GPa}$ for $\mathrm{Li}_{2} \mathrm{C}_{2}$ and $40 \mathrm{GPa}$ for $\mathrm{BaC}_{2}$, irreversible amorphization is observed. I. Efthimiopouls et al. figured out that this may relate to the PIP of isolated $\mathrm{C}_{2}{ }^{2-}$ dumbbells into a network [62]. The amorphization of the acetylides under high pressure prohibits the crystallographic investigation, and other new techniques are needed to find an unambiguous conclusion. By compressing $\mathrm{CaC}_{2}$, we found the electrical conductivity was enhanced by $10^{7}$-fold irreversibly and the band gap was compressed to $0 \mathrm{eV}$ at $18 \mathrm{GPa}$ (Figure 3a), which is attributed to the enhancement of the interaction between $\mathrm{C}_{2}{ }^{2-}$ units during compression and the polymerization of acetylide anions [63]. To find direct evidence, we used the gas chromatography-mass spectroscopy (GC-MS) to examine the calcium carbide $\left(\mathrm{CaC}_{2}\right)$ recovered from $26 \mathrm{GPa}$. The principle is that the hydrolysis of the polymerized $\mathrm{C}_{\mathrm{m}}{ }^{\mathrm{x}-}$ anions in the recovered sample will produce $\mathrm{C}_{2 n} \mathrm{H}_{2 n}$ according to the chemical reaction equation: $\mathrm{Ca}_{n} \mathrm{C}_{2 n}+2 \mathrm{nH}_{2} \mathrm{O}=\mathrm{nCa}(\mathrm{OH})_{2}+\mathrm{C}_{2 n} \mathrm{H}_{2 n}$, which could be recognized by GC-MS and the original product composition can hence be deducted. The results showed that the product contained the benzene molecules, which indicated that the $\mathrm{CaC}_{2}$ polymerized to form $\mathrm{C}_{6}{ }^{6-}$ under high pressure (Figure $3 \mathrm{~b}$ ). Besides these, some other complex molecules such as $\mathrm{C}_{3} \mathrm{H}_{4}$, $\mathrm{C}_{5} \mathrm{H}_{6}, \mathrm{C}_{5} \mathrm{H}_{4}, \mathrm{C}_{6} \mathrm{H}_{8}, \mathrm{C}_{6} \mathrm{H}_{6}, \mathrm{C}_{6} \mathrm{H}_{4}$, and $\mathrm{C}_{8} \mathrm{H}_{7}$ were detected in the gas phase, while more complicated molecules like $\mathrm{C}_{12} \mathrm{H}_{12}, \mathrm{C}_{12} \mathrm{H}_{10}$, and $\mathrm{C}_{12} \mathrm{H}_{14}$ were observed in the liquid phase. The $\mathrm{C}: \mathrm{H}$ ratio of most molecules was around 1:1, which means the non-ox/red polymerization dominated the reaction process. By checking the corresponding mass spectrum in the National Institute of Standards and Technology (NIST) library, we found these molecules included linear and cyclic polycarbide structures. It was 
consistent with the prediction that showed the carbides convert to chain, belt and sheet with increasing pressure (Figure 3c). This is the first experimental work showing the solid evidence that acetylide can polymerize under high pressure. Based on the GC-MS results and the standard working curve, we found that the conversion rate of this polymerization reaction was above $11 \%$. This work also highlights that GC-MS is a very effective method to analyze the amorphous carbon-species recovered from high pressure.

(a)

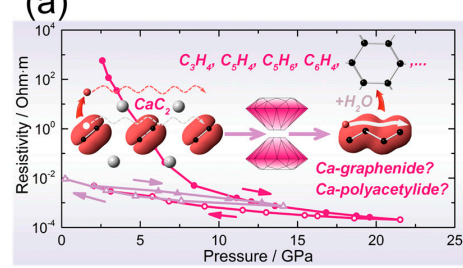

(b)
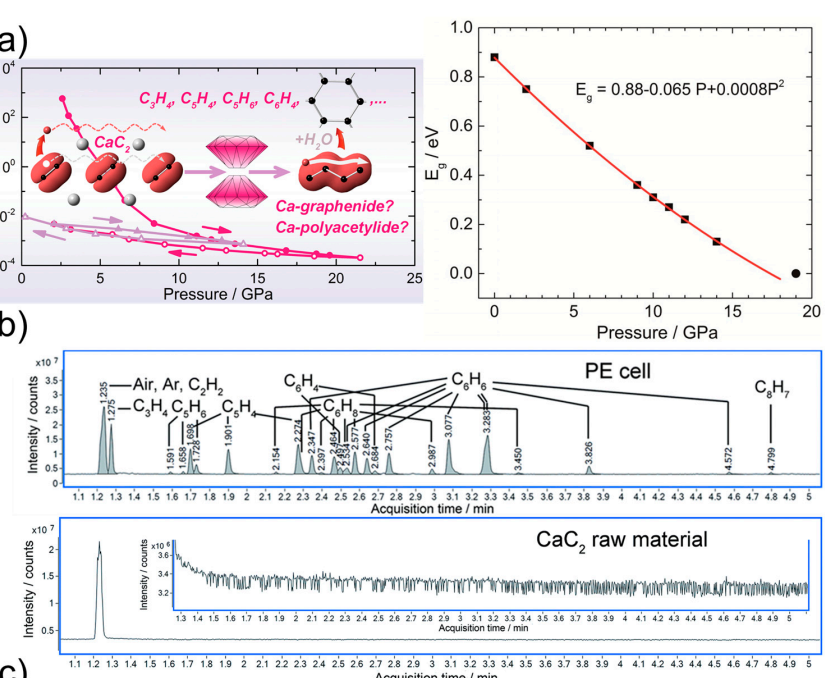

(c)

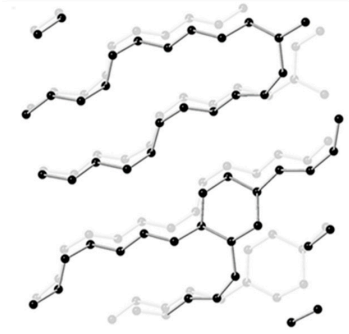

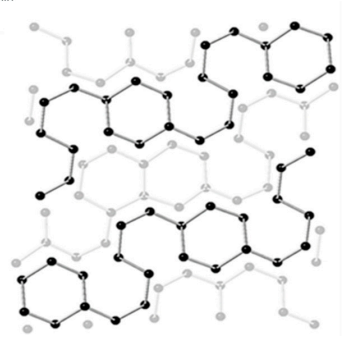

Figure 3. (a) The pressure dependent electrical resistivity and band gap of $\mathrm{CaC}_{2}$ [63]. (b) Total ion chromatograms of the product of $\mathrm{CaC}_{2}$ recovered from $26 \mathrm{GPa}$ and raw material reacting with water [63].

(c) Simulated structure of $\mathrm{CaC}_{2}$ at $30 \mathrm{GPa}$ by meta-dynamics [63].

The more complicated reaction was observed in the PIP of lithium acetylides $\left(\mathrm{Li}_{2} \mathrm{C}_{2}\right)$, which was accompanied by disproportionation processes. $\mathrm{Li}_{2} \mathrm{C}_{2}$ was reported to transform from Immm phase to Pnma phase and amorphized at higher pressure, which probably contains the polymerization process [61]. We made further investigation by combining the spectral measurements and theoretical prediction [64]. The IR data showed two new peaks at 1187 and $1296 \mathrm{~cm}^{-1}$ at $27 \mathrm{GPa}$ (Figure 4a), which were recognized as the in-plane transverse mode and longitudinal mode of charged carbon ribbons in lithium polyacenide (Figure 4b). During decompression, the peaks at 1636 and $1733 \mathrm{~cm}^{-1}$ were identified as the $C-C$ stretching vibration of the $C_{3}$ anions, which means $\mathrm{Li}$ propenide $\mathrm{Li}_{6} \mathrm{C}_{3}-\mathrm{C} 2 / \mathrm{m}$ and $\mathrm{Li}$ allenide $\mathrm{Li}_{4} \mathrm{C}_{3}-\mathrm{C} 2 / \mathrm{m}$ are presented in the amorphous product. The peaks observed at $1100 \mathrm{~cm}^{-1}$ were ascribed to the in-plane transverse mode and longitudinal mode of the charged carbon ribbons in the $\mathrm{Li}_{3} \mathrm{C}_{4}$-Immm fragments (Figure $4 \mathrm{~b}$ ). Thus, the behavior of $\mathrm{Li}_{2} \mathrm{C}_{2}$ under high pressure was summarized in the following sequence. The $\mathrm{Li}_{2} \mathrm{C}_{2}$-Immm-dimmer transformed to phase Pnma-dimmer and then polymerized into $\mathrm{Li}_{2} \mathrm{C}_{2}$ ribbon structure. This structure was not thermodynamically stable and disproportionated into a carbon-rich phase $\left(\mathrm{Li}_{3} \mathrm{C}_{4}\right)$ and Li-rich phase $\left(\mathrm{Li}_{4} \mathrm{C}_{3}\right.$ and $\left.\mathrm{Li}_{6} \mathrm{C}_{3}\right)$ during decompression (Figure 4c). This polymerization and disproportionation process were also evidenced by GC-MS. The results showed the product has the ring structure, which is constant with the ribbon structure of the Li polycarbide. The C:H ratio of the products significantly deviated from 1:1, which demonstrated the disproportionation process. For the Li-C system described above, when compressing 
$\mathrm{Li}_{2} \mathrm{C}_{2}$ up to $27.5 \mathrm{GPa}$, the sample became amorphous as observed in XRD. However, when heated up, the Bragg peaks appear and sharpen again (Figure 5a), which were recognized as crystalline $\mathrm{LiC}_{2}$ (Figure 5b) [65]. This phenomenon was also observed at $36.5 \mathrm{GPa}, 1800 \mathrm{~K}$ (Figure 5c). The product is $\mathrm{Li}_{3} \mathrm{C}_{4}$ with a polyacenide structure (Figure $5 \mathrm{~d}$ ). The disproportion reaction is accelerated and completed under high temperature, while the meta-stable phase like $\mathrm{Li}_{2} \mathrm{C}_{2}$ (ribbon) decomposes.

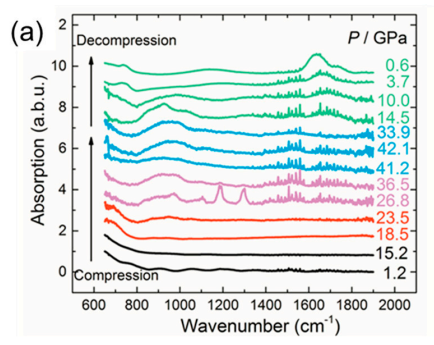

(b)

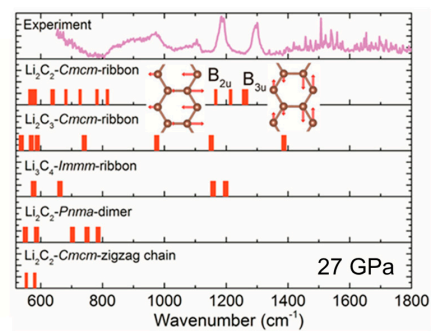

(c)
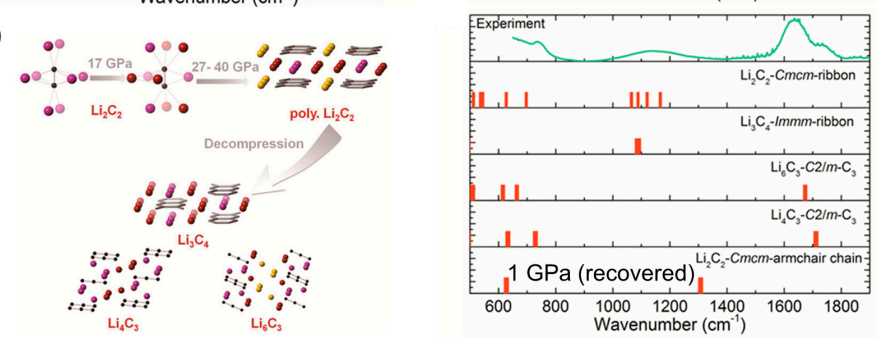

Figure 4. (a) In situ IR spectrum of $\mathrm{Li}_{2} \mathrm{C}_{2}$ during compression and decompression process [64]. (b) Experiment data and theoretical simulations of selected phases at $27 \mathrm{GPa}$ and $1 \mathrm{GPa}$ (recovered) [64]. (c) The phase transition and reaction process of $\mathrm{Li}_{2} \mathrm{C}_{2}$ under high pressure [64].

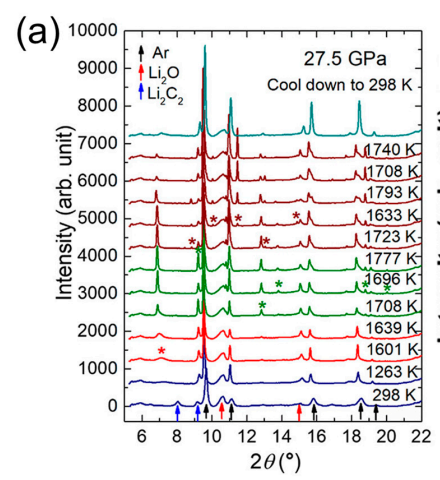

(b)
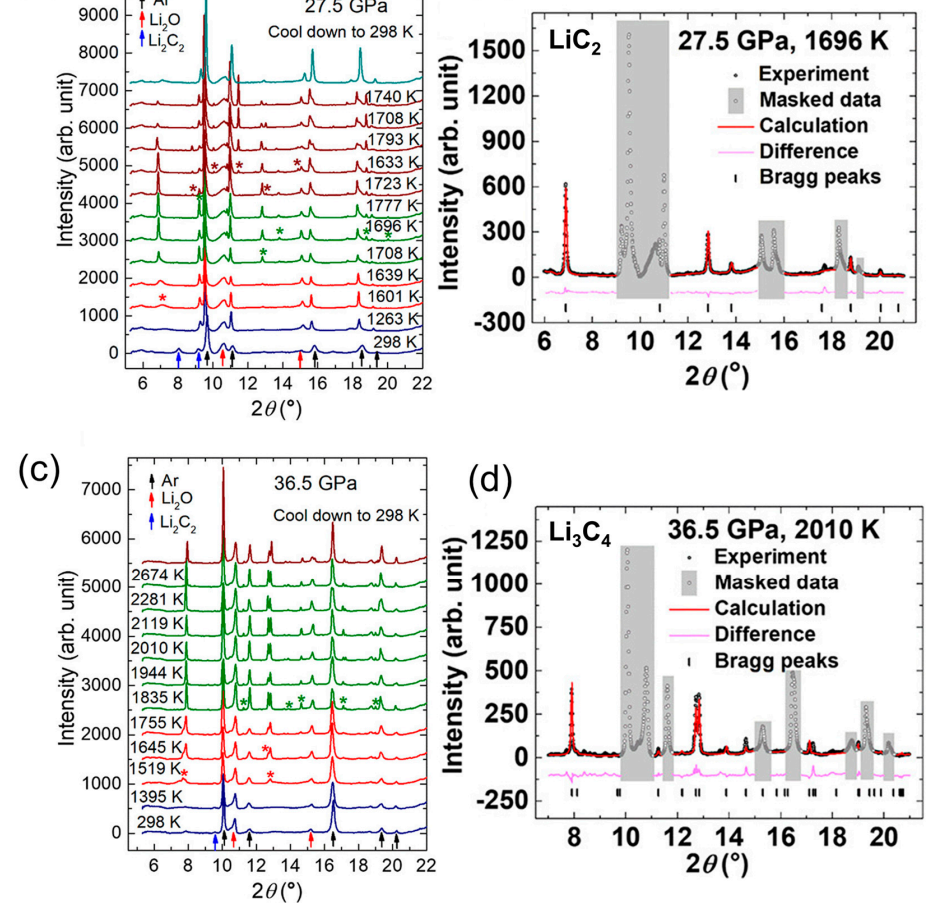

Figure 5. In situ X-ray powder diffraction (XRD) patterns of $\mathrm{Li}_{2} \mathrm{C}_{2}$ at (a) 27.5 and (c) $36.5 \mathrm{GPa}$ under high temperature [65]. Rietveld refinement plots of $(\mathbf{b}) \mathrm{LiC}_{2}$ and (d) $\mathrm{Li}_{3} \mathrm{C}_{4}$ under $27.5 \mathrm{GPa}, 1696 \mathrm{~K}$ and 36.5 GPa, $2010 \mathrm{~K}$, respectively [65]. 


\subsection{Cyanide}

Cyanide contains unsaturated carbon-nitrogen triple bond. For example, $\mathrm{NaCN}$, a simple alkali metal cyanide, polymerized at $25 \mathrm{GPa}$ after three phase transitions [66]. The polymer exhibits a broad Raman band centered at $1550 \mathrm{~cm}^{-1}$ which indicates the formation of $\mathrm{C}=\mathrm{N}$ bonds. Prussian blue $\mathrm{Fe}\left[\mathrm{Co}(\mathrm{CN})_{6}\right]$ also undergoes polymerization upon compression and the sample recovered at $17.4 \mathrm{GPa}$ shows similar Raman spectrum with that of an amorphous $\mathrm{CN}_{\mathrm{x}}$ film [67]. $\mathrm{K}_{3} \mathrm{Fe}(\mathrm{CN})_{6}$ is another important cyanide compound, which is well-studied in coordination chemistry and electrochemistry. It polymerized at a much lower pressure, around $4 \mathrm{GPa}$ [68]. That is to say, the reaction pressures of transition metal cyanides are much lower than that of alkali cyanides. We investigated the PIP of $\mathrm{K}_{3} \mathrm{Fe}(\mathrm{CN})_{6}$ using in situ Raman (Figure 6a), XRD (Figure 6b) and AC impedance (Figure 6c) techniques. $\mathrm{K}_{3} \mathrm{Fe}(\mathrm{CN})_{6}$ undergoes reversible phase transition $(\mathrm{O} 1-\mathrm{O} 2)$ at 2-4 GPa with an increase of conductivity [69]. At 7-8 GPa, an irreversible phase transition O2-O3 occurs with a decrease in conductivity. Finally, the sample becomes amorphous irreversibly at $\sim 12 \mathrm{GPa}$. The structure details of the precursors and products are from the in situ neutron diffraction (Figure 6d), in situ X-ray absorption fine structure (XAFS) (Figure 6e) and neutron pair distribution function (PDF) (Figure 6f). The results show the reaction of the cyanide anions follow a sequence of approaching, bonding, and stabilizing (Figure 6g) [70]. In the O1-O2 phase transition, two $\mathrm{CN}$ anions react inside $\mathrm{Fe}(\mathrm{CN})_{6}{ }^{3-}$ and results in weak $\mathrm{C} \ldots \mathrm{C}$ bond and the $\mathrm{CN}$ triple bonds are greatly weakened and elongated. From $\mathrm{O} 2$ to $\mathrm{O} 3$, an electron transfers from cyanide anions to $\mathrm{Fe}$ (III), which reduces the charge density of $\mathrm{CN}^{-}$and makes this polymerization process irreversible. Thus, it clearly indicates that the transition metal brings the $\mathrm{CN}$ closer and decrease the charge density, which will make the charged monomers react at a much lower pressure. This provides an important insight for designing and synthesizing new materials through PIP.

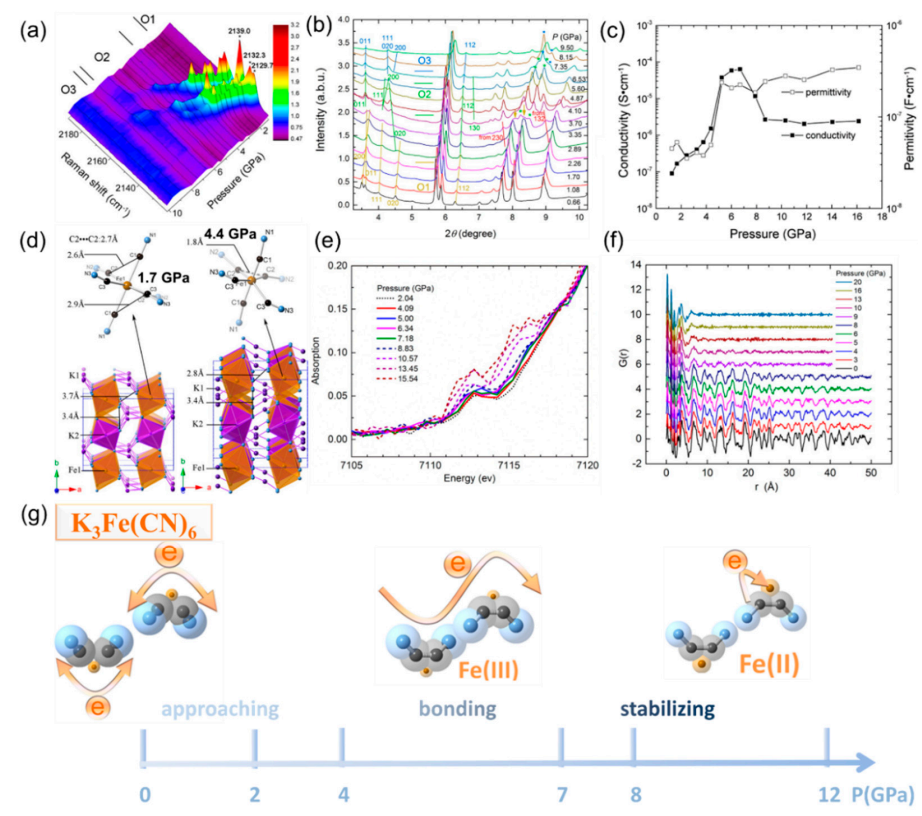

Figure 6. (a) In situ Raman spectrum of $\mathrm{K}_{3} \mathrm{Fe}(\mathrm{CN})_{6}$ under high pressure up to $10 \mathrm{GPa}$ [69]. (b) Selected in situ X-ray diffraction patterns of $\mathrm{K}_{3} \mathrm{Fe}(\mathrm{CN})_{6}$, the peaks of $\mathrm{O} 1-\mathrm{O} 3$ are marked by yellow arrows, green stars, and blue squares, respectively [69]. (c) Electronic conductivity and permittivity of $\mathrm{K}_{3} \mathrm{Fe}(\mathrm{CN})_{6}$ under high pressure [69]. (d) Crystal structure of $\mathrm{K}_{3} \mathrm{Fe}(\mathrm{CN})_{6}$ and local structure of $\mathrm{Fe}(\mathrm{CN})_{6}{ }^{3-}$ obtained from in situ neutron diffraction [70]. (e) In situ X-ray absorption fine structure (XAFS) spectrum of $\mathrm{K}_{3} \mathrm{Fe}(\mathrm{CN})_{6}$ under high pressure [70]. (f) Neutron PDF $(\mathrm{G}(\mathrm{r}))$ of $\mathrm{K}_{3} \mathrm{Fe}(\mathrm{CN})_{6}$ recovered from different pressures. (g) Phase transition and chemical reaction process of $\mathrm{K}_{3} \mathrm{Fe}(\mathrm{CN})_{6}$ under high pressure [70]. 
To further decrease the pressure, we select the $\mathrm{Li}_{3} \mathrm{Fe}(\mathrm{CN})_{6}$ as the precursor, which has smaller interspaced cations. The polymerization pressure was successfully decreased to $1 \mathrm{GPa}$ and the irreversible reaction pressure was around $4-5 \mathrm{GPa}$, which can be industrially achieved [71]. Compared with $\mathrm{K}_{3} \mathrm{Fe}(\mathrm{CN})_{6}$, another step of reaction accompanied with a further increase of conductivity was observed at $10 \mathrm{GPa}$, suggesting the degree of polymerization of $\mathrm{Li}_{3} \mathrm{Fe}(\mathrm{CN})_{6}$ is higher than that of $\mathrm{K}_{3} \mathrm{Fe}(\mathrm{CN})_{6}$.

A trimerization process involving three cyanide groups from different dicyanamide ions to form a tricyanomelaminate ring was reported in some nitride compounds [72-74]. The behavior of $\mathrm{LiN}(\mathrm{CN})_{2}$ under high pressure was studied by Raman spectroscopy, infrared spectroscopy and XRD [75]. Infrared and Raman spectrum data show that $\operatorname{LiN}(\mathrm{CN})_{2}$ begins to undergo a phase transition at 7.5-9 GPa, but the original peaks related to molecular crystal does not change significantly in frequency and intensity, suggesting that this is a new polymorph. When the pressure is greater than $18 \mathrm{GPa}$, the spectral data changes significantly, suggesting the reaction occurs. The peaks of $1450 \mathrm{~cm}^{-1}$ and $1550 \mathrm{~cm}^{-1}$ in the IR are similar to the peaks of triazine ring formation in $\mathrm{Li}_{3} \mathrm{C}_{6} \mathrm{~N}_{9}[74,76,77]$, indicating that the sample undergoes a similar reaction mechanism and formed a polymerized extended structure. The observed $\mathrm{C} \equiv \mathrm{N}$ stretching, ring rotation modes and a broad band in the region of $\mathrm{sp}^{2} \mathrm{C}=\mathrm{N} / \mathrm{C}=\mathrm{C}$ stretching also support this view. After $14 \mathrm{~h}$ annealing of samples at $20 \mathrm{GPa}$ and $373 \mathrm{~K}$, it was found that the $\mathrm{C} \equiv \mathrm{N}$ peaks disappeared in the recovered products, and the D band, $\mathrm{G}$ band with two ring vibrational modes at $745 \mathrm{~cm}^{-1}$ and $1021 \mathrm{~cm}^{-1}$ were observed, which are similar to melamine [78,79]. Unlike other cyanogen materials, the decompression product is still transparent, possibly because the remaining $\mathrm{Li}$ ions in the structure prevent long scale polymerization.

\section{Unsaturated Organic Compounds}

Like ionic compounds, the intermolecular distance of molecular compounds is also reduced and the intermolecular interactions are greatly enhanced under external pressure. Most molecules crystallize under high pressure and their diffusion will be inhibited. When the intermolecular interactions reach some threshold, a chemical reaction may occur and result in new bonding connections. The unsaturated groups like carbon double bond [80], triple bond [81], cyano group [82], carbonyl group [83] and aromatic ring [84] can be activated without catalyst and transform into saturated compounds irreversibly. The reaction is obviously affected by the molecular orientation and crystal structure. That is to say, the reaction usually happened in a topochemical way, ideally from crystal to crystal. In practice, the products obtained are usually locally ordered or amorphous due to the defect of the sample and the non-uniformity of the high-pressure environment. The characterizations of the products and mechanism description are the key points of research. Here, we will introduce some typical reactions of molecular compounds under high pressure.

\subsection{Alkene}

Ethylene $\left(\mathrm{C}_{2} \mathrm{H}_{4}\right)$ is the simplest organic molecule containing a double bond. All the atoms are on the same plane, and each $\mathrm{sp}^{2}$ carbon exhibits a geometric shape of a plane triangle and forms a $\mathrm{H}-\mathrm{C}-\mathrm{H}$ bond angle of $117^{\circ}$ [85]. The polymerization pathway of alkenyl groups is greatly affected by the molecular position and relative orientation in the crystal. At 3.6 GPa, the kinetic data indicate that the polymerization occurs along a preferential direction (possibly the a-axis), thus obtaining the high-density crystalline polymer. More complex evolution of the growth process with increasing pressure was predicted because of the comparable distance between the molecules along the axis and diagonal of the unit cell. This will result in the branching of the chains and low-density polyethylene was obtained at $5.4 \mathrm{GPa}$ [86]. When combing with the continuous-wave laser with the $\lambda \leq 460 \mathrm{~nm}$, the reaction pressure was decreased to $1 \mathrm{GPa}$ and a highly crystalline polyethylene with high density was obtained. This process contains a two-photon absorption process and the variety of molecular geometry will facilitate the formation of the polymeric chain [87]. 
Another example of the PIP combining with the laser irradiation is that of butadiene $\left(\mathrm{C}_{4} \mathrm{H}_{6}\right)$. The laser irradiation has two effects: changing the reaction pathway and lowering the reaction pressure. At $0.7 \mathrm{GPa}$, the solid butadiene $\left(\mathrm{C}_{4} \mathrm{H}_{6}\right)$ only dimerizes to vinylcyclohexene by cycloaddition reaction [88]. By irradiation with the laser of $488 \mathrm{~nm}$ at $0.8 \mathrm{GPa}$, the dimerization was inhibited and the pure trans-polybutadiene was synthesized [80]. This photochemical reaction contains a two-photon transition process. At the excitation state, the free rotation of the terminal $-\mathrm{CH}_{2}$ group is possible and the bond lengths of $\mathrm{C} 1-\mathrm{C} 2$ and $\mathrm{C} 3-\mathrm{C} 4$ increase which will be beneficial for the polymerization along the molecular backbone.

\subsection{Alkyne}

Acetylene $\left(\mathrm{C}_{2} \mathrm{H}_{2}\right)$ is the simplest alkyne, which polymerizes to form polyacetylene in the presence of the Zieglar-Natta catalysts [89]. Under external pressure, acetylene crystallized into cubic phase at $0.7 \mathrm{GPa}$ and formed an orthorhombic phase at $0.9 \mathrm{GPa}$. Above $3.5 \mathrm{GPa}$, it polymerizes without catalyst [90] and more branched polyacetylene is produced when irradiated by laser [91]. At $77 \mathrm{~K}$, acetylene polymerizes at about $11 \mathrm{GPa}$, and mainly produces cis-polyacetylene [92], which isomerizes to the trans-isomer when warmed to room temperature. Based on the calculated crystal structure of acetylene, the possible reaction route was proposed, but the selectivity of cis-polyacetylene could not be explained by the bonding route along the face diagonal of the $a-b$ plane proposed in the literature [89-93]. By collecting the in situ high-pressure neutron diffraction data, the crystal structure (Figure 7a) at the threshold reaction pressure, 5.7 GPa, was determined [94]. Another reaction route along the face diagonal of the $a-c$ plane is figured out, in which the $C \ldots C$ distance is also around $3.1 \AA$ (Figure 7a). On this plane, regardless of whether the chain grows along the $a+c / a-c$ direction or alternately along $a+c$ and $a-c$, cis-PA will be produced. This reaction route is also confirmed by the theoretical simulation. At lower pressure, amorphous polyacetylene will be produced (Figure 7b). At higher pressure, cis-polyacetylene will be produced first, which will transfer into the saturated cyclic layered structure (Figure 7c). It is very interesting to point out when we start the simulation from the obtained cis-polyacetylene crystal under external pressure, we could get graphane (Figure 7d). These predictions were confirmed by the nuclear magnetic resonance (NMR) and PDF results of the $\mathrm{C}_{2} \mathrm{H}_{2}$ recovered from $10 \mathrm{GPa}$, which demonstrated the route from acetylene to graphane, and more substituted graphane can be expected from the PIP of substituted alkynes (Figure 7e).

When the acetylene formed 1:1 cocrystal with benzene at high pressure, the reaction pressure is obviously increased. The polymerization pressure is at least about $28 \mathrm{GPa}$, which was significantly higher than the $3.5 \mathrm{GPa}$ of pure acetylene. A mixed amorphous and crystalline hydrocarbons were obtained when heating the co-crystal at $30 \mathrm{GPa}$ and $200^{\circ} \mathrm{C}$. The high-resolution transmission electron microscope (HRTEM) and fast Fourier transform (FFT) show it is consistent with a cubic unit cell with lattice parameter $\mathrm{a} \approx 4.2 \AA$ which matches the structure of $i$-carbon [95]. Considering the presence of the hydrogen atoms, the $\mathrm{K}_{4}-\mathrm{CH}$ is a promising candidate structure. The proposed reaction mechanism is containing the $2+2$ cycloaddition reaction between the benzene molecules without acetylene participating. 
(a)
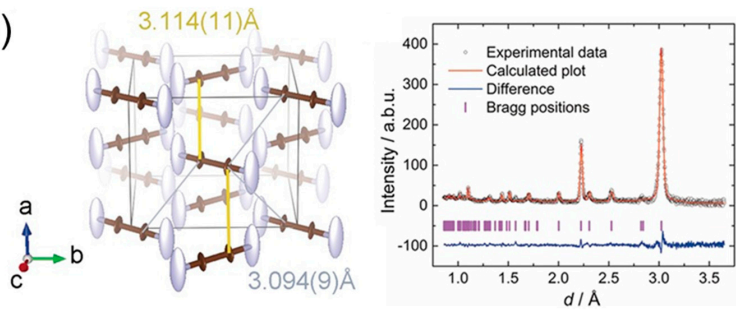

(b)

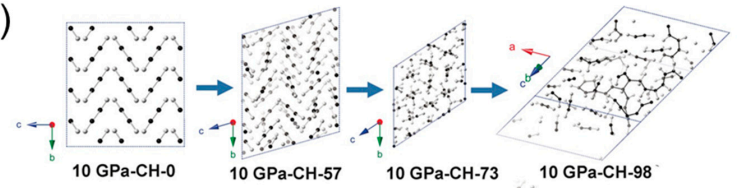

(c)

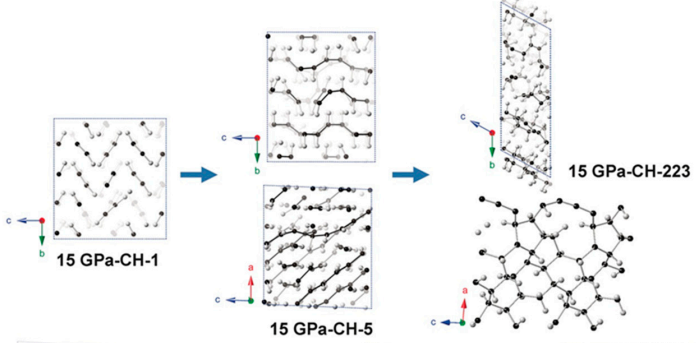

(d)

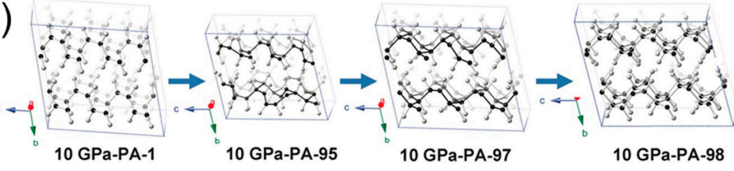

(e)
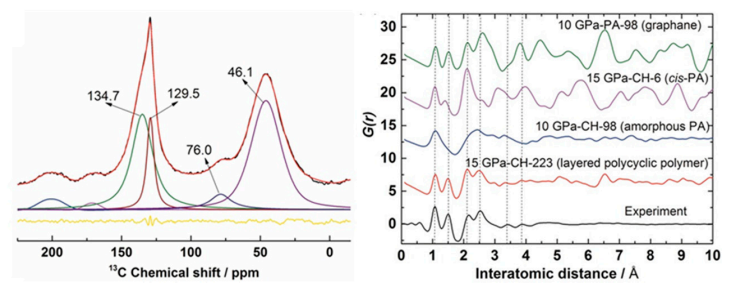

Figure 7. (a) Crystal structure (left) and Rietveld refinement plot (right) of acetylene at $5.7 \mathrm{GPa}$, carbon and nitrogen are shown in brown and light blue ellipses, the shortest distance between the carbon atoms in adjacent molecules are indicated by yellow and brown lines [94]. Metadynamic simulation results of acetylene under (b) $10 \mathrm{GPa}$ and (c) $15 \mathrm{GPa}$ [94]. (d) Metadynamic simulation results of cis-polyacetylene under $10 \mathrm{GPa}$ [94]. (e) The solid state nuclear magnetic resonance (left) and neutron PDF experiment data (right) of acetylene recovered from $10 \mathrm{GPa}$ and the modeled PDFs G(r) of selected structural models of the metadynamic simulations shown in b, c, d [94].

Motivated by synthesizing the polyacetylene backbone with highly electronegative substituents, the behavior of $\mathrm{C}_{2} \mathrm{I}_{2}$ under high pressure was studied. $\mathrm{C}_{2} \mathrm{I}_{2}$ underwent a phase transition from tetragonal $\mathrm{P}_{2} / n$ to orthorhombic $\mathrm{Cmca}$ around $0.3 \mathrm{GPa}$. The Raman and IR spectrum data show that the samples begin to polymerize above $4 \mathrm{GPa}$ with the color darkening and completely opaque. The formation of new $C-C$, conjugated $C=C$ and $C=C=C$, as well as the weakened $C$-I stretching mode, were observed in the IR spectrum, which suggests the formation of an extended aromatic or conjugated $\mathrm{C}=\mathrm{C}$ system [96]. The polymerized products exhibit good electrical conductivity, which provides insights into the synthesis of new conductive materials. Polymerization of diynes under the ambient light, UV or $\gamma$-ray irradiation or by heating are the general methods to synthesize poly (diacetylenes), which can be used in optical switches, optical limiters, and high-resolution photoresists [97]. Sometimes it cannot react under above conditions due to the limitation of molecular geometry. PIP may be an effective method to initiate the reaction and control the orderly topological polymerization. Christopher Wilhelm et al. studied the high-pressure polymerization of diiodobutadiyne cocrystals that form with two kinds of bis(pyridyl)oxalamides (cocrystal 3 with the 3-pyridyl host and 4 with 4-pyridyl host) 
(Figure 8) [98]. XRD data indicate that the cocrystal 3 polymerized at 1 GPa while the cocrystals 4 experienced a phase transition at $3 \mathrm{GPa}$. In the Raman spectrum, three new peaks were observed in two kinds of cocrystals, which are similar to the known polymers, suggesting the two cocrystals polymerized. In order to further understand the composition of the recovered samples, solid-phase ${ }^{13} \mathrm{C}$ magic-angle spinning NMR was studied and the spectra before and after compression were compared. For recovered cocrystal 3, the peak of the monomer disappeared, and two new peaks appeared near $110 \mathrm{ppm}$ and $89 \mathrm{ppm}$. Similar new peaks were observed in cocrystal 4, but there were still strong monomer peaks. These results show that after compression, the cocrystal with host 3 contains $>90 \%$ polymer, while only $\sim 55 \%$ for cocrystal 4 . The different reaction pressure of 3 and 4 is closely related to the molecular geometry in the crystal structure. In the co-crystal 3, both the repeat distance and the $\mathrm{C} 1-\mathrm{C} 4^{\prime}$ distance are within the desired range, while for the co-crystal 4 , the initial structure is far from the desired parameters for polymerization. Thus, no reaction is observed until after the pressure-induced phase transition.

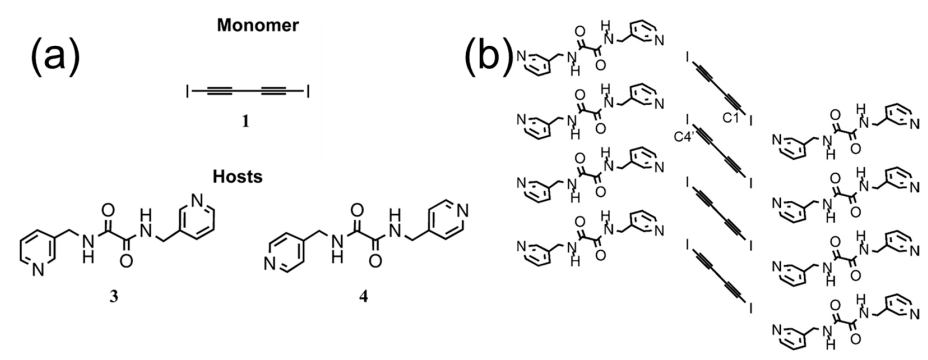

Figure 8. (a) The structure of diiodobutadiyne and 3-pyridyl host, 4-pyridyl host [98]. (b) The structure of cocrystal 4 [98].

\subsection{Aromatic Compounds}

Benzene was widely studied in high-pressure chemistry, which was reported to react at the pressure of 20-25 GPa [99,100]. The recovered products are white solid and become orange, red and finally black when heated [101]. Several techniques including Raman and IR spectroscopy were explored to investigate the product, which shows it is an amorphous C:H network containing both $\mathrm{sp}^{2}$ and $\mathrm{sp}^{3}$-bonded carbon [102] and the aromaticity of the benzene ring was destroyed. This process mainly takes place during the decompression process, and radical species are contained in the reaction [100]. Recently, Thomas C. Fitzgibbons et al. obtained a crystalline one-dimensional $\mathrm{sp}^{3}$ carbon nanomaterial when compressing benzene molecules at a relatively slow rate [103]. Further research shows the uniaxial stress is the key factor in helping the polycrystalline or single-crystalline benzene monomer to transform into single-crystalline packings of carbon nanothreads [104]. The theoretical groups tried to investigate the reaction mechanism. Lucia Ciabini et al. proposed that the lattice phonons play a key role in triggering chemical reactions. They found that the threshold reaction distance in PIP of benzene is about $2.6 \AA$ (after correction of thermal vibration) [105]. At this distance, the $\sigma$-bond and the zwitterion species are formed and the reaction is initiated. Based on the possible nanothread structure, Bo Chen et al. proposed the potential reaction routes like the [4+2] reaction and para polymerization mechanism. The energies of the formed dimers were also examined to evaluate the corresponding reaction [106].

Based on these results, we studied the benzene-hexafluorobenzene $\left(\mathrm{C}_{6} \mathrm{H}_{6}-\mathrm{C}_{6} \mathrm{~F}_{6}\right)$ cocrystal under high pressure. In this co-crystal system, half of the $\mathrm{C}_{6} \mathrm{H}_{6}$ molecules were replaced by $\mathrm{C}_{6} \mathrm{~F}_{6}$, which provides a tracer during the reaction. Compared with benzene, it has stronger $\pi \ldots \pi$ stacking interactions, which will facilitate the reaction between the aromatic molecules. By carefully detecting the intermediate recovered from high pressure, we gave more experimental evidence for the elemental reactions in the PIP process of aromatics $[107,108]$. Under high pressure, the $\mathrm{C}_{6} \mathrm{H}_{6}-\mathrm{C}_{6} \mathrm{~F}_{6}$ co-crystal underwent four-phase transitions at $\sim 0.5,1.7,3.7,11.3 \mathrm{GPa}$ and polymerized above $20 \mathrm{GPa}$ [107]. By combing in situ synchrotron XRD, constant wavelength and time of flight (TOF) neutron diffraction, 
we determined the structures of all the high-pressure phases $a b$ initio. At $20 \mathrm{GPa}$, close to the reaction pressure, the $\mathrm{C}_{6} \mathrm{~F}_{6}$ and $\mathrm{C}_{6} \mathrm{H}_{6}$ are still stacked alternately to form columns in a tilted way (Figure $9 \mathrm{a}$ ). The nearest $\mathrm{C} \ldots \mathrm{C}$ distance between the $\mathrm{C}_{6} \mathrm{H}_{6}$ and $\mathrm{C}_{6} \mathrm{~F}_{6}$ in the column is around $2.8 \AA$ (before correction of thermal vibration). The products recovered from $20 \mathrm{GPa}$ were analyzed by the scanning electron microscope (SEM) (Figure 9b), transmission electron microscope (TEM) (Figure 9c) and solid-state NMR (ssNMR) (Figure 9d), suggesting the product has layered graphitic skeleton constructed by $\mathrm{C}$ $\left(\mathrm{sp}^{3}\right), \mathrm{F}$ and $\mathrm{H}$ atoms. The X-ray PDF and IR spectrum (Figure 9e) gave a definitive proof that the recovered polymers fit a short-range ordered hydrogenated-fluorinated graphitic model. The reaction intermediates were extracted and measured by GC-MS. Based on the results, we deduced that the elemental reaction contains the [4+2] Diels-Alder, retro-Diels-Alder, and 1-1' coupling reactions. The [4+2] Diels-Alder is the key reaction in the PIP process. Thus, the whole process can be described; the alternately stacked $\mathrm{C}_{6} \mathrm{~F}_{6}-\mathrm{C}_{6} \mathrm{H}_{6}$ forms the [4+2] polymer ribbons, which connect to their neighbors to form $\mathrm{H}-\mathrm{F}$ graphane with a layered structure by eliminating some $\mathrm{C}, \mathrm{H}$, and $\mathrm{F}$ species (Figure 9f). These elemental reactions indicated in this system will provide an insight to understand the other aromatics under extreme conditions.

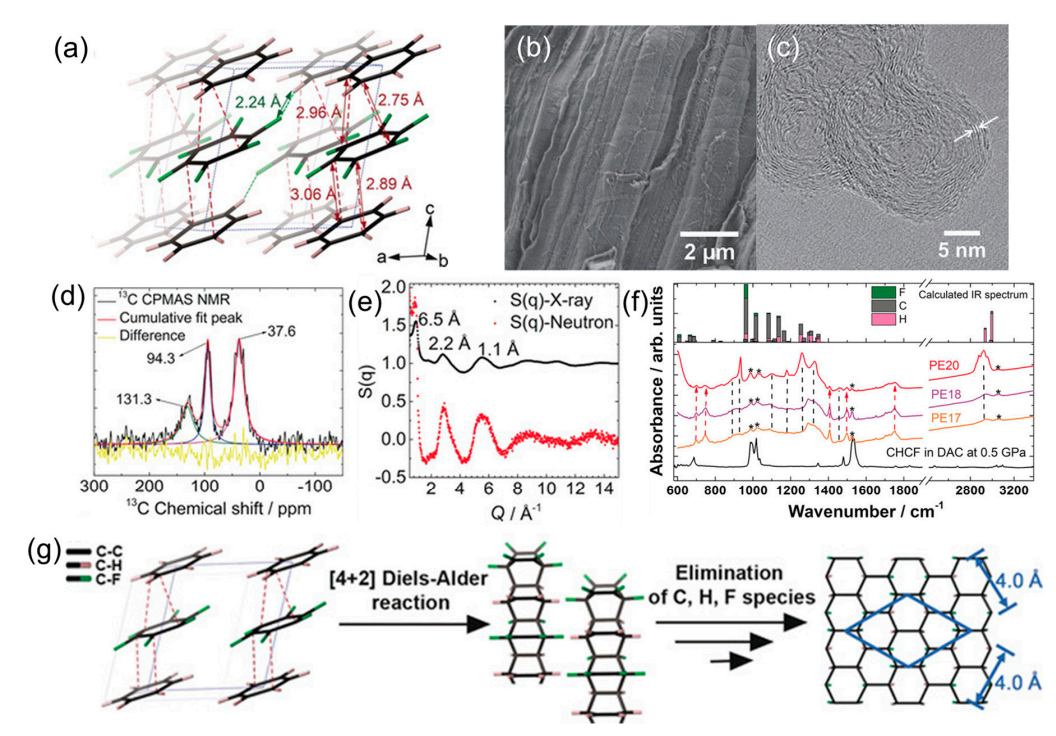

Figure 9. (a) The crystal structure of $\mathrm{C}_{6} \mathrm{D}_{6}-\mathrm{C}_{6} \mathrm{~F}_{6}$ before reaction (20 GPa) [108]. (b) Scanning electron microscope (SEM) images, (c) transmission electron microscope (TEM) images, (d) ${ }^{13} \mathrm{C}$ cross-polarization magic-angle-spinning solid state NMR (CPMAS ssNMR) spectrum and (e) the synchrotron X-ray with neutron PDF data of $\mathrm{C}_{6} \mathrm{H}_{6}-\mathrm{C}_{6} \mathrm{~F}_{6}$ recovered from $20 \mathrm{GPa}$ [108]. (f) IR absorption spectrum of starting material (black), $\mathrm{C}_{6} \mathrm{H}_{6}-\mathrm{C}_{6} \mathrm{~F}_{6}$ cocrystal recovered from $17 \mathrm{GPa}$ (orange), $18 \mathrm{GPa}$ (purple), $20 \mathrm{GPa}$ (red), and the calculated IR spectrum of the H-F graphane model [108]. (g) The proposed reaction route from $\mathrm{C}_{6} \mathrm{H}_{6}-\mathrm{C}_{6} \mathrm{~F}_{6}$ cocrystal to $\mathrm{H}$, F-graphane [108].

The PIP of other aromatic compounds like pyridine and aniline were also investigated. Aniline constructed molecular crystal using its intermolecular hydrogen bonds. The combination of XRD, IR and UV spectrum data showed that the aniline molecule was stable at least $30 \mathrm{GPa}$ at room temperature, which may be attributed to the hydrogen bond arrangement [8]. After UV laser irradiation, a chain-like alkane polymeric structure was formed, which converted into a 3D amorphous extended network at higher pressure with longer irradiation. At $30 \mathrm{GPa}, 550 \mathrm{~K}$, aniline was found to react gradually and continue to occur during the downstroke. In combination with TEM and density functional theory (DFT), it was found that the product is a $\mathrm{NH}_{2}$-enriched carbon nanothreads with diamond-like structure [109]. When reducing pressure to 10-20 GPa before heating, a different hydrogenated graphitic carbon nitride was generated [110]. Through further analysis of the reaction mechanism, it is found that both these two reactions follow a topochemical path but occurs in different directions under 
different pressure. Because of the anisotropic compressibility of the unit cell determined by the effect of $\mathrm{H}$-bonds, at lower pressure, molecules react along the $b c$ plane which is favor the formation of a layered structure, while reacting along the $a$-axis at higher pressure will result in the nanothread. In addition, the reactive distance of $2.49 \AA$ of aniline is consistent with benzene [105] and triazine [111], suggesting its popularity. Those studies show that the stress anisotropy can be induced to gain crystalline product, and high temperature is also an important way to facilitate the crystallization. This provides new insights for the synthesis of new carbon materials.

Zhuravlev et al. reported five reversible phase transitions of pyridine at 1, 2, 8, 11, and $16 \mathrm{GPa}$ [38], and above $22 \mathrm{GPa}$, an irreversible conversion occurred. Through detailed analysis of the product by Raman and IR spectrum, Fanetti et al. observed the formation of $\mathrm{sp}^{3}$ carbon in the recovered product relief from $22 \mathrm{GPa}$ [112]. In addition, they found laser could effectively reduce the threshold pressure. Yasuzuka et al. revisited the behavior of pyridine under high pressure, found a new solid-solid phase transition at $5.0 \mathrm{GPa}$, and confirmed the previously reported transitions around 1.2 (solidification), 1.6, 8.2 , and $10 \mathrm{GPa}$. When pyridine is compressed to above $20 \mathrm{GPa}$, the sample color turns to dark yellow and can be recovered as a yellow-brown solid material under environmental conditions. XRD data showed that the recovered samples contained a certain amount of crystalline components, but they did not identify specific substances [113]. Xiang Li et al. recently obtained ordered $\mathrm{sp}^{3} \mathrm{C}_{5} \mathrm{NH}_{5}$ carbon nitride nanothreads through the compression and decompression of pyridine [114]. The IR peak at $1117 \mathrm{~cm}^{-1}$ is identified as inter-ring $\mathrm{C}-\mathrm{N}$ stretching, which suggests the polymerization of pyridine. Combined with the theoretical simulation, the synchrotron $\mathrm{X}$-ray diffraction patterns of products are in good agreement with the predicted six-fold single-crystal diffraction pattern of a representative tube $(3,0) \_123456$ carbon nitride nanothread. The ${ }^{15} \mathrm{~N}$ and ${ }^{13} \mathrm{C}$ solid-state NMR spectrum indicates significant conversion from $\mathrm{sp}^{2}$ to $\mathrm{sp}^{3}$ bonding during polymerization.

Bini et al. determined that the reaction of furane occurred up to $10 \mathrm{GPa}$ [115]. Like that of benzene, the reaction accelerated in the decompression stage and a yellow-brown product was obtained. IR spectrum showed that recovered product is a kind of amorphous carbon-containing alkylpolyether type segment, and the presence of $\mathrm{O}-\mathrm{H}$ groups in the product suggests a hydrogen transfer. The effect of laser on furane reaction was also studied. It was found that laser could effectively reduce the threshold pressure down to $3.5 \mathrm{GPa}$ and induce the reaction to produce large amounts of carbon dioxide and the larger amount of carbonyl groups, which is different from that induced by pressure alone [116]. Mario Santoro et al. explained that the different reaction mechanisms is due to the different molecular arrangements in the different pressure region. However, the structures of the high-pressure phases of furane are not known to confirm this assumption.

\subsection{Nitriles}

Nitriles contain $\mathrm{C} \equiv \mathrm{N}$ bonds and usually have a large dipole moment. Dipole-dipole interactions and in some cases hydrogen bonding usually determine the arrangement of molecules in a crystal [17]. The typical example is HCN molecules, which crystallize into head-to-tail aligned linear chains by strong hydrogen bonds and stacked into a tetragonal structure [117]. Above $1 \mathrm{GPa}, \mathrm{HCN}$ crystal polymerized to form black products. It was proposed that the polymer is quite similar to azulmic acid 5 identified by Volker, which consists of linearly condensed hexagonal $\mathrm{C}_{5} \mathrm{~N}$ rings with amino and $\mathrm{CN}$ side groups $[17,118]$. The presence of amino groups indicated that the reaction involves hydrogen transfer process. This hydrogen transfer reaction was also observed in the acetonitrile.

$\left(\mathrm{CH}_{3} \mathrm{CN}\right)$ molecules, which have weak $\mathrm{CH} \ldots \mathrm{NC}$ hydrogen bonds [119]. The in situ IR data (Figure 10a) shows a yellowish polymer with the $\mathrm{C}=\mathrm{C} / \mathrm{C}=\mathrm{N}$ bond and the amino group was formed above $23 \mathrm{GPa}$. The polymer of the milligram scale was synthesized by PE cell and the product is identified as ammonia gas and black solid powder. The neutron PDF shows that the product is a graphitic polymer with multilayered carbon onion structure (Figure 10b). Aromatic carbon, $\mathrm{C}=\mathrm{C}\left(\mathrm{NR}_{2}\right)_{2}$ group, $\mathrm{sp}^{3}$ carbon and aminated carbon $\left(\mathrm{NR}_{2}-\mathrm{CR}_{3}\right)$ were observed in the solid-state NMR (Figure 10c) and no methyl groups were detected, which means the methyl group participates in 
the hydrogen transfer reaction. To understand the reaction process, in situ neutron diffraction was carried out. The results show at $20.6 \mathrm{GPa}$, the acetonitrile molecules are linked by the - $\mathrm{CN} \ldots \mathrm{HCH}_{2}$ hydrogen bond to form an intercalated diamond-type network (Figure 10d). The distance of the $\mathrm{D}$... N is around $1.98 \AA$, shorter than the sum of van der Waals radii of nitrogen and hydrogen by $28 \%$, suggesting the high possibility of hydrogen migration through the hydrogen bond. The whole reaction process was confirmed by theoretical calculations, which showed the C-H bonds were activated by the cyano group, forming amino groups and dimer adducts (Figure 10e). Then, the dimer reacts to form a 1D chain and then a nanoribbon structure. The structure containing the amino groups is ready to eliminate ammonia gas at appropriate conditions. Besides $\mathrm{HCN}$ and $\mathrm{CH}_{3} \mathrm{CN}$, other nitriles like cyanogen [120], tetracyanoethylene (TCNE) [121], phosphorous tricyanide $\left(\mathrm{P}(\mathrm{CN})_{3}\right)$ [122], tetracyanomethane $\left(\mathrm{C}(\mathrm{CN})_{4}\right)$ [123] and dicyanoacetylene [124] also polymerize under high pressure. The additional polymerization of the nitriles group to form the $\mathrm{C}=\mathrm{N}$ is the typical reaction in the above systems. The products are recognized as the two-dimensional polycyclic network comprised of $\mathrm{sp}^{2}$ carbon with "pyrrolic" and "pyridinic-like" nitrogen or networks comprised of ring structure and $\mathrm{sp}^{3}$ center.

(a)

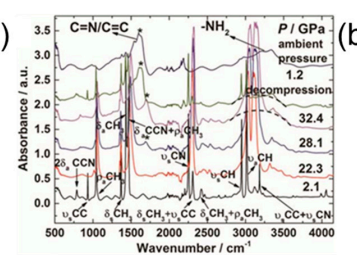

(c)

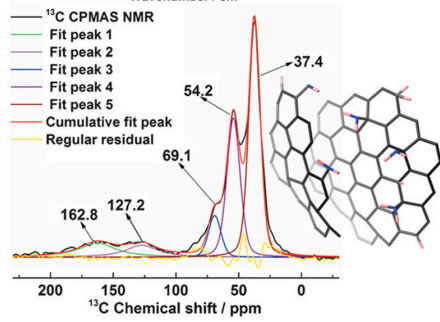

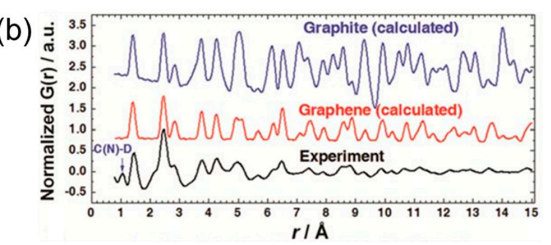

(d)

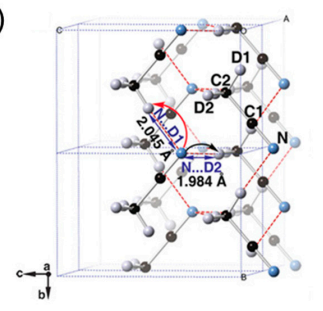

(e)
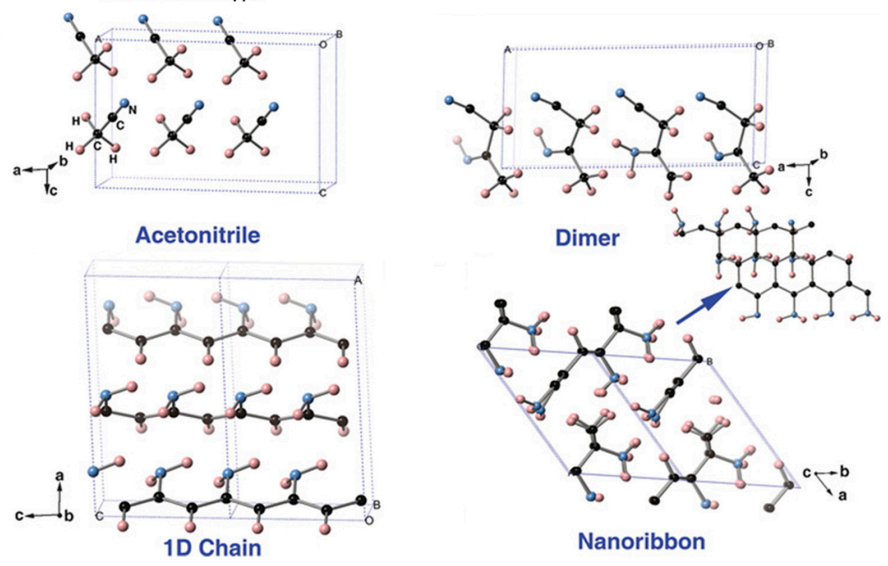

Figure 10. (a) In situ IR spectrum of $\mathrm{CH}_{3} \mathrm{CN}$ during compression and decompression [119]. (b) Experimental PDF (G(r)) of D-graphitic polymer recovered from $25 \mathrm{GPa}$ and modeled PDF $(\mathrm{G}(\mathrm{r}))$ of graphite and graphene models [119]. (c) ${ }^{13} \mathrm{C}$ CPMAS ssNMR spectrum of graphite polymer. (d) Crystal structure of $\mathrm{CD}_{3} \mathrm{CN}$ at 20.6 GPa [119]. (e) The possible reaction process of acetonitrile under high pressure indicated by metadynamic calculations at $35 \mathrm{GPa}$ [119].

\section{Conclusions}

In this review, the typical high-pressure devices, high-pressure characterization techniques and chemical reactions of typical compounds containing unsaturated carbon atoms under high pressure are introduced. Compared with those under atmospheric pressure, the chemical behaviors of compounds 
under high pressure change greatly and many unexcepted carbon materials are produced. Due to the volume contraction, the compounds with a higher coordination number (more saturated) will be formed under high pressure. Products are usually partially crystalline or amorphous. For the reaction under high pressure, the diffusion of the molecules is significantly hindered, which promotes the bonding between the neighbored atoms. This will make the reaction mechanisms quite different from that in "free" condition under ambient pressure. The reaction is mainly affected by the crystal structure before the reaction and determined by the critical distance at the threshold pressure, showing topochemical properties. In situ and ex situ characterization method as well as the theoretical simulation play a critical role to understand the whole reaction process. For the perspective, more detailed theoretical research and development of characterization techniques like time-resolve techniques are still needed to uncover the reaction mechanisms. For tailored synthesis, more accurate reaction conditions need to be controlled, like the pressure, temperature conditions, compression and decompression rate, the crystallinity of reactant, the stress and hydrostatic condition. Deep understanding of the reaction mechanisms and clear relationship between the reactant, reaction condition and the product will make the high pressure synthesis of carbon materials more designable, which will provide a novel dimension for chemistry and material research.

Author Contributions: Investigation, X.Y.; writing-original draft, X.Y., X.W. and Y.W.; figure drawing, X.Y.; conceptualization, H.Z.; supervision, H.Z.; funding acquisition, H.Z. and K.L.; writing-review and editing, all authors.

Funding: This research was funded by National Natural Science Foundation of China (NSFC) (Grant Nos.: 21875006 and 21771011). The authors also acknowledge the support from the Top 1000-Talents Award.

Acknowledgments: The authors acknowledge the support of the National Natural Science Foundation of China (NSFC) (grant nos. 21875006 and 21771011). The authors also acknowledge the support from the Top 1000-Talents Award.

Conflicts of Interest: The authors declare no conflict of interest.

\section{References}

1. Mao, H.-K.; Chen, B.; Chen, J.; Li, K.; Lin, J.-F.; Yang, W.; Zheng, H. Recent advances in high-pressure science and technology. Matter Radiat. Extrem. 2016, 1, 59-75. [CrossRef]

2. Lei, L.; Zhang, L. Recent advance in high-pressure solid-state metathesis reactions. Matter Radiat. Extrem. 2017, 3, 95-103. [CrossRef]

3. Bini, R. Laser-assisted high-pressure chemical reactions. Acc. Chem. Res. 2004, 37, 95-101. [CrossRef] [PubMed]

4. Evans, W.J.; Lipp, M.J.; Yoo, C.-S.; Cynn, H.; Herberg, J.L.; Maxwell, R.S. Pressure-induced polymerization of carbon monoxide: Disproportionation and synthesis of an energetic lactonic polymer. Chem. Mater. 2006, 18, 2520-2531. [CrossRef]

5. Iota, V.; Yoo, C.-S.; Cynn, H. Quartzlike carbon dioxide: An optically nonlinear extended solid at high pressures and temperatures. Science 1999, 283, 1510-1513. [CrossRef] [PubMed]

6. Eremets, M.I.; Hemley, R.J.; Mao, H.-K.; Gregoryanz, E. Semiconducting non-molecular nitrogen up to 240 GPa and its low-pressure stability. Nature 2001, 411, 170-174. [CrossRef]

7. Gorelli, F.A.; Santoro, M.; Ulivi, L.; Bini, R. The epsilon phase of solid oxygen: Evidence of an $\mathrm{O}_{4}$ molecule lattice. Phys. Rev. Lett. 1999, 83, 4093-4096. [CrossRef]

8. Nobrega, M.M.; Temperini, M.L.A.; Bini, R. Probing the chemical stability of aniline under high pressure. J. Phys. Chem. C 2017, 121, 7495-7501. [CrossRef]

9. Bassett, W.A. Diamond anvil cell, 50th birthday. High Pressure Res. 2009, 29, 163-186. [CrossRef]

10. Xu, J.-A.; Mao, H.-K. Moissanite: A window for high-pressure experiments. Science 2000, 290, 783-785. [CrossRef]

11. Xu, J.-A.; Huang, E. Graphite-diamond transition in gem anvil cells. Rev. Sci. Instrum. 1994, 65, 204-207. [CrossRef] 
12. Zhang, J.; Zhao, X.; Yan, Z.; Yuan, Y.; Li, X.; Pei, Z.H.; Wang, L. In situ high-pressure spectroscopic studies using moissanite (4H-SiC) anvils. AIP Adv. 2018, 8, 095012. [CrossRef]

13. Xu, J.-A.; Mao, H.-K.; Bell, P.M. High-pressure ruby and diamond fluorescence: Observations at 0.21 to 0.55 terapascal. Science 1986, 232, 1404-1406. [CrossRef] [PubMed]

14. Mao, H.-K.; Xu, J.-A.; Bell, P.M. Calibration of the ruby pressure gauge to 800 kbar under quasi-hydrostatic conditions. J. Geophys. Res. 1986, 91, 4673-4676. [CrossRef]

15. Barnett, J.D.; Block, S.; Piermarini, G.J. An optical fluorescence system for quantitative pressure measurement in the diamond-anvil cell. Rev. Sci. Instrum. 1973, 44, 1-4. [CrossRef]

16. Forman, R.A.; Piermarini, G.J.; Barnett, J.D.; Block, S. Pressure measurement made by the utilization of ruby sharp-line luminescence. Science 1972, 176, 284-285. [CrossRef] [PubMed]

17. Schettino, V.; Bini, R. Molecules under extreme conditions: Chemical reactions at high pressure. Phys. Chem. 2003, 5, 1951-1965.

18. Akahama, Y.; Kawamura, H. Pressure calibration of diamond anvil Raman gauge to 310 GPa. J. Appl. Phys. 2006, 100, 043516. [CrossRef]

19. Piermarini, G.J.; Block, S.; Barnett, J.D. Hydrostatic limits in liquids and solids to 100 kbar. J. Appl. Phys. 1973, 44, 5377-5382. [CrossRef]

20. Ragan, D.D.; Clarke, D.R.; Schiferl, D. Silicone fluid as a high-pressure medium in diamond anvil cells. Rev. Sci. Instrum. 1996, 67, 494. [CrossRef]

21. Kenichi, T. Evaluation of the hydrostaticity of a helium-pressure medium with powder X-ray diffraction techniques. J. Appl. Phys. 2001, 89, 662-668.

22. Besson, J.M.; Nelmes, R.J. New developments in neutron-scattering methods under high pressure with the Paris-Edinburgh cells. Physica B 1995, 231, 31-36. [CrossRef]

23. Marshall, W.G.; Francis, D.J. Attainment of near-hydrostatic compression conditions using the Paris-Edinburgh cell. J. Appl. Cryst. 2002, 35, 122-125. [CrossRef]

24. Kono, Y.; Park, C.; Kenney-Benson, C.; Shen, G.; Wang, Y. Toward comprehensive studies of liquids at high pressures and high temperatures: Combined structure, elastic wave velocity, and viscosity measurements in the Paris-Edinburgh cell. Phys. Earth Planet. Inter. 2014, 228, 269-280. [CrossRef]

25. Wang, Y. Large volume presses for high-pressure studies using synchrotron radiation. In High-Pressure Crystallography; Boldyreva, E., Dera, P., Eds.; Springer: Berlin, Germany, 2010; pp. 81-96.

26. Liebermann, R.C. Multi-anvil, high pressure apparatus: A half-century of development and progress. High Press. Res. 2011, 31, 493-532. [CrossRef]

27. Mao, H.-K.; Chen, X.J.; Ding, Y.; Li, B.; Wang, L. Solids, liquids, and gases under high pressure. Rev. Mod. Phys. 2018, 90, 015007. [CrossRef]

28. Shen, G.; Mao, H.-K.; Hemley, R.J. Laser-Heated Diamond Anvil Cell Technique: Double-Sided Heating with Multimode Nd:YAG Laser. In Advanced Materials '96-New Trend in High Pressure Research, Proceedings of the 3rd NIRIM ISAM, Tsukuba, Japan, 4-8 March 1996; Akaishi, M., Ed.; National Institute for Research in Inorganic Materials: Tokyo, Japan, 1996; pp. 149-152.

29. Smith, D.; Smith, J.S.; Childs, C.; Rod, E.; Hrubiak, R.; Shen, G.; Salamat, S. A CO 2 laser heating system for in situ high pressure-temperature experiments at HPCAT. Rev. Sci. Instrum. 2018, 89, 083901. [CrossRef]

30. Heinz, D.L.; Jeanloz, R. Measurement of the melting curve of $\mathrm{Mg}_{0.9} \mathrm{Fe}_{0.1} \mathrm{SiO}_{3}$ at lower mantle conditions and its geophysical implications. Phys. Earth Planet. Inter. 1987, 92, 11437-11444.

31. Heinz, D.L.; Sweeney, J.S. A laser heating system that stabilizes and controls the temperature: Diamond anvil cell applications. Rev. Sci. Instrum. 1991, 62, 1568-1575. [CrossRef]

32. Bassett, W.A.; Shen, A.H.; Bucknum, M. A new diamond anvil cell for hydrothermal studies to $2.5 \mathrm{GPa}$ and from $-190{ }^{\circ} \mathrm{C}$ to $1200{ }^{\circ} \mathrm{C}$. Rev. Sci. Instrum. 1993, 64, 2340-2345. [CrossRef]

33. Kantor, I.; Prakapenka, V.; Kantor, A.; Dera, P.; Kurnosov, A. BX90: A new diamond anvil cell design for $\mathrm{X}$-ray diffraction and optical measurements. Rev. Sci. Instrum. 2012, 83, 125102. [CrossRef] [PubMed]

34. Chen, J.; Zheng, H.; Xiao, W. High-temperature and high-pressure cubic zirconia cell for Raman spectroscopy. Appl. Spectrosc. 2003, 57, 1295-1299. [CrossRef] [PubMed]

35. Hirsch, K.R.; Holzapfel, W.B. Effect of high pressure on the Raman spectra of ice VIII and evidence for ice X. J. Chem. Phys. 1986, 84, 2771-2775. [CrossRef] 
36. Gardiner, D.J.; Bowden, M.; Graves, P.R. Novel applications of Raman microscopy. Phil. Trans. R. Soc. Lond. A 1986, 320, 295-306. [CrossRef]

37. Dreger, Z.A.; Gupta, Y.M. High pressure Raman spectroscopy of single crystals of hexahydro-1,3,5-trinitro-1,3,5-triazine (RDX). J. Phys. Chem. C 2007, 111, 3893-3903. [CrossRef] [PubMed]

38. Zhuravlev, K.K.; Traikov, K.; Dong, Z.; Xie, S.; Song, Y. Raman and infrared spectroscopy of pyridine under high pressure. Phys. Rev. B 2010, 82, 064116. [CrossRef]

39. Dong, Y.; Zhang, J.; Tan, X.; Wang, L.; Chen, J.; Li, B.; Ye, L.; Xu, B.; Zou, B.; Tian, W. Multi-stimuli responsive fluorescence switching: The reversible piezochromism and protonation effect of a divinylanthracene derivative. J. Mater. Chem. C 2013, 1, 7554-7559. [CrossRef]

40. He, C.; Gao, C.; Ma, Y.; Li, M.; Hao, A.; Huang, X.; Liu, B.; Zhang, D.; Yu, C.; Zou, G.; et al. In situ electrical impedance spectroscopy under high pressure on diamond anvil cell. Appl. Phys. Lett. 2007, 91, 092124. [CrossRef]

41. Han, Y.; Gao, C.; Ma, Y.; Liu, H.; Pan, Y.; Luo, J.; Li, M.; He, C.; Huang, X.; Zou, G.; et al. Integrated microcircuit on a diamond anvil for high-pressure electrical resistivity measurement. Appl. Phys. Lett. 2005, 86, 064104. [CrossRef]

42. Mao,H.-K.; Bell, P.M. Electrical resistivity measurements of conductors in the diamond-window, high-pressure cell. Rev. Sci. Instrum. 1998, 52, 615-616. [CrossRef]

43. Hamlin, J.J.; Jeffries, J.R.; Butch, N.P.; Syers, P.; Zocco, D.A.; Weir, S.T.; Vohra, Y.K.; Paglione, J.; Maple, M.B. High pressure transport properties of the topological insulator $\mathrm{Bi}_{2} \mathrm{Se}_{3}$. J. Phys. Condes. Matter. 2012, 24, 035602. [CrossRef]

44. Yamauchi, T.; Shimizu, K.; Takeshita, N.; Ishizuka, M.; Amaya, K.; Endo, S. Hall effect of iodine in high pressure. J. Phys. Soc. Jpn. 1994, 63, 3207-3209. [CrossRef]

45. Lee, M.; Rosenbaum, T.F.; Saboungi, M.-L.; Schnyders, H.S. Band-gap tuning and linear magnetoresistance in the silver chalcogenides. Phys. Rev. Lett. 2002, 88, 066602. [CrossRef]

46. Vaccari, M.; Aquilanti, G.; Pascarelli, S.; Mathon, O. A new EXAFS investigation of local structural changes in amorphous and crystalline $\mathrm{GeO}_{2}$ at high pressure. J. Phys. Condens. Matter. 2009, 21, 145403. [CrossRef]

47. Rueff, J.-P.; Mattila, A.; Badro, J.; Vankó, G.; Shukla, A. Electronic properties of transition-metal oxides under high pressure revealed by X-ray emission spectroscopy. J. Phys. Condens. Matter. 2005, 17, S717-S726. [CrossRef]

48. Lee, S.K.; Lin, J.-F.; Cai, Y.Q.; Hiraoka, N.; Eng, P.J.; Okuchi, T.; Mao, H.-K.; Meng, Y.; Hu, M.Y.; Chow, P.; et al. X-ray Raman scattering study of $\mathrm{MgSiO}_{3}$ glass at high pressure: Implication for triclustered $\mathrm{MgSiO}_{3}$ melt in Earth's mantle. Proc. Natl. Acad. Sci. USA 2008, 105, 7925-7929. [CrossRef]

49. Machida, S. Neutron diffraction experiments at high pressure in SNS. Rev. High. Pres. Sci. Tech. 2016, 26, 157-166. [CrossRef]

50. Hattori, T.; Sano-Furukawa, A.; Arima, H.; Komatsu, K.; Yamada, A.; Inamura, Y.; Nakatani, T.; Seto, Y.; Nagai, T.; Utsumi, W.; et al. Design and performance of high-pressure PLANET beamline at pulsed neutron source at J-PARC. Nucl. Instrum. Methods Phys. Res. A 2015, 780, 55-67. [CrossRef]

51. Bull, C.L.; Funnell, N.P.; Tucker, M.G.; Hull, S.; Francis, D.J.; Marshall, W.G. Pearl: The high pressure neutron powder diffractometer at ISIS. High Press. Res. Int. J. 2016, 36, 493-511. [CrossRef]

52. Klotz, S.; Besson, J.M.; Hamel, G.; Nelmes, R.J.; Loveday, J.S.; Marshall, W.G. High pressure neutron diffraction using the Paris-Edinburgh cell: Experimental possibilities and future prospects. High Press. Res. Int. J. 1996, 14, 249-255. [CrossRef]

53. Goncharenko, I.N.; Mirebeau, I.; Ochiai, A. Magnetic neutron diffraction under pressures up to 43 GPa. Study of the EuX and GdX compounds. Hyperfine Interact. 2000, 128, 225-244. [CrossRef]

54. Guthriea, M.; Boehlera, R.; Tulk, C.A.; Molaison, J.J.; Dos Santos, A.M.; Li, K.; Hemley, R.J. Neutron diffraction observations of interstitial protons in dense ice. Proc. Natl. Acad. Sci. USA 2013, 110, 10552-10556. [CrossRef] [PubMed]

55. Utsumi, W.; Kagi, H.; Komatsu, K.; Arima, H.; Nagai, T.; Okuchi, T.; Kamiyama, T.; Uwatoko, Y.; Matsubayashi, K.; Yagi, T. Neutron powder diffraction under high pressure at J-PARC. Nucl. Instrum. Methods Phys. Res. Sect. A 2009, 600, 50-52. [CrossRef]

56. Goncharenko, I.N. Neutron diffraction experiments in diamond and sapphire anvil cells. High Press. Res. Int. J. 2004, 24, 193-204. [CrossRef] 
57. Presser, V.; Heon, M.; Gogotsi, Y. Carbide-derived carbons-from porous networks to nanotubes and graphene. Adv. Funct. Mater. 2011, 21, 810-833. [CrossRef]

58. Benson, D.; Li, Y.; Luo, W.; Ahuja, R.; Svensson, G.; Haussermann, U. Lithium and calcium carbides with polymeric carbon structures. Inorg. Chem. 2013, 52, 6402-6406. [CrossRef]

59. Srepusharawoot, P.; Blomqvist, A.; Araújo, C.M.; Scheicher, R.H.; Ahuja, R. One-dimensional polymeric carbon structure based on five-membered rings in alkaline earth metal dicarbides $\mathrm{BeC}_{2}$ and $\mathrm{MgC}_{2}$. Phys. Rev. B 2010, 82, 125439. [CrossRef]

60. Li, Y.-L.; Wang, S.-N.; Oganov, A.R.; Gou, H.; Smith, J.S.; Strobel, T.A. Investigation of exotic stable calcium carbides using theory and experiment. Nat. Commun. 2015, 6, 6974. [CrossRef]

61. Efthimiopoulos, I.; Benson, D.E.; Konar, S.; Nylen, J.; Svensson, G.; Haussermann, U.; Liebig, S.; Ruschewitz, U.; Vazhenin, G.V.; Loa, I.; et al. Structural transformations of $\mathrm{Li}_{2} \mathrm{C}_{2}$ at high pressures. Phys. Rev. B 2015, 92, 064111. [CrossRef]

62. Efthimiopoulos, I.; Kunc, K.; Vazhenin, G.V.; Stavrou, E.; Syassen, K.; Hanfland, M.; Liebig, S.; Ruschewitz, U. Structural transformation and vibrational properties of $\mathrm{BaC}_{2}$ at high pressure. Phys. Rev. B 2012, 85, 054102. [CrossRef]

63. Zheng, H.; Wang, L.; Li, K.; Yang, Y.; Wang, Y.; Wu, J.; Dong, X.; Wang, C.-H.; Tulk, C.A.; Molaison, J.J.; et al. Pressure induced polymerization of acetylide anions in $\mathrm{CaC}_{2}$ and $10^{7}$ fold enhancement of electrical conductivity. Chem. Sci. 2017, 8, 298-304. [CrossRef]

64. Wang, L.; Dong, X.; Wang, Y.; Zheng, H.; Li, K.; Peng, X.; Mao, H.-K.; Jin, C.; Meng, Y.; Huang, M.; et al. Pressure-induced polymerization and disproportionation of $\mathrm{Li}_{2} \mathrm{C}_{2}$ accompanied with irreversible conductivity enhancement. J. Phys. Chem. Lett. 2017, 8, 4241-4245. [CrossRef]

65. Dong, X.; Wang, L.; Li, K.; Zheng, H.; Wang, Y.; Meng, Y.; Shu, H.; Mao, H.-K.; Feng, S.; Jin, C. Tailored synthesis of the narrowest zigzag graphene nanoribbon structure by compressing the lithium acetylide under high temperature. J. Phys. Chem. C 2018, 122, 20506-20512. [CrossRef]

66. Chena, J.-Y.; Yoo, C.-S. Physical and chemical transformations of sodium cyanide at high pressures. J. Chem. Phys. 2009, 131, 144507. [CrossRef]

67. Catafesta, J.; Haines, J.; Zorzi, J.E.; Pereira, A.S.; Perottoni, C.A. Pressure-induced amorphization and decomposition of Fe[Co(CN) 6 ]. Phys. Rev. B 2008, 77, 064104. [CrossRef]

68. Hara, Y.; Shirotani, I.; Minomura, S. Changes of the electronic state and the electrical resistance of some iron compounds at high pressures. Inorg. Chem. 1975, 14, 1834-1837. [CrossRef]

69. Li, K.; Zheng, H.; Ivanov, I.N.; Guthrie, M.; Xiao, Y.; Yang, W.; Tulk, C.A.; Zhao, Y.; Mao, H.-K. K3 Fe(CN)6: Pressure-induced polymerization and enhanced conductivity. J. Phys. Chem. C 2013, 117, 24174-24180. [CrossRef]

70. Li, K.; Zheng, H.; Wang, L.; Tulk, C.A.; Molaison, J.J.; Feygenson, M.; Yang, W.; Guthrie, M.; Mao, H.-K. $\mathrm{K}_{3} \mathrm{Fe}(\mathrm{CN})_{6}$ under external pressure: Dimerization of $\mathrm{CN}^{-}$coupled with electron transfer to $\mathrm{Fe}(\mathrm{III})$. J. Phys. Chem. C 2015, 119, 22351-22356. [CrossRef]

71. Li, K.; Zheng, H.; Hattori, T.; Sano-Furukawa, A.; Tulk, C.A.; Molaison, J.; Feygenson, M.; Ivanov, I.N.; Yang, W.; Mao, H.-K. Synthesis, structure, and pressure-Induced polymerization of $\mathrm{Li}_{3} \mathrm{Fe}(\mathrm{CN})_{6}$ accompanied with enhanced conductivity. Inorg. Chem. 2015, 54, 11276-11282. [CrossRef]

72. Jurgens, B.; Irran, E.; Schneider, J.; Schnick, W. Trimerization of $\mathrm{NaC}_{2} \mathrm{~N}_{3}$ to $\mathrm{Na}_{3} \mathrm{C}_{6} \mathrm{~N}_{9}$ in the Solid: $\mathrm{Ab}$ initio crystal structure determination of two polymorphs of $\mathrm{NaC}_{2} \mathrm{~N}_{3}$ and of $\mathrm{Na}_{3} \mathrm{C}_{6} \mathrm{~N}_{9}$ from X-ray powder diffractometry. Inorg. Chem. 2000, 39, 665-670. [CrossRef]

73. Cairns, T.L.; Larchar, A.W.; McKusick, B.C. The trimerization of nitriles at high pressures. J. Am. Chem. Soc. 1952, 74, 5633-5636. [CrossRef]

74. Purdy, A.P.; Houser, E.; George, C.F. Lithium dicyanamide, its reactions with cyanuric chloride, and the crystal structures of $\mathrm{LiN}(\mathrm{CN})_{2}(\mathrm{MeCN})_{2}$ and $\mathrm{LiCN}\left(\mathrm{C}_{5} \mathrm{H}_{5} \mathrm{~N}\right)_{2}$. Polyhedron 1997, 16, 3671-3679. [CrossRef]

75. Keefer, D.W.; Gou, H.; Purdy, A.P.; Epshteyn, A.; Kim, D.Y.; Badding, J.V.; Strobel, T.A. Pressure-induced polymerization of LiN(CN)2. J. Phys. Chem. A 2016, 120, 9370-9377. [CrossRef]

76. Lotsch, B.V.; Schnick, W. From triazines to heptazines: Novel nonmetal tricyanomelaminates as precursors for graphitic carbon nitride materials. Chem. Mater. 2006, 18, 1891-1900. [CrossRef]

77. Li, X.; Zhang, J.; Shen, L.; Ma, Y.; Lei, W.; Cui, Q.; Zou, G. Preparation and characterization of graphitic carbon nitride through pyrolysis of melamine. Appl. Phys. A Mater. Sci. Process. 2009, 94, 387-392. [CrossRef] 
78. Koglin, E.; Kip, B.J.; Meier, R.J. Adsorption and displacement of melamine at the Ag/electrolyte interface probed by surface-enhanced Raman microprobe spectroscopy. J. Phys. Chem. 1996, 100, 5078-5089. [CrossRef]

79. Andreyev, A.; Akaishi, M.; Golberg, D. Synthesis of nanocrystalline nitrogen-rich carbon nitride powders at high pressure. Diamond. Relat. Mater. 2002, 11, 1885-1889. [CrossRef]

80. Citroni, M.; Ceppatelli, M.; Bini, R.; Schettino, V. Laser-induced selectivity for dimerization versus polymerization of butadiene under pressure. Science 2002, 295, 2058-2060. [CrossRef]

81. Bartlett, R.K.; Neill, G.O.; Turner, H.S.; Wall, W.F. High pressure polymerisation of acetylenic compounds. Br. Polym. J. 1972, 4, 503-509. [CrossRef]

82. Yamawaki, H.; Aoki, K.; Kakudate, Y.; Yoshida, M.; Usuba, S.; Fujiwara, S. Infrared study of phase transition and chemical reaction in tetracyanoethylene under high pressure. Chem. Phys. Lett. 1992, 198, $183-187$. [CrossRef]

83. Bernard, S.; Chiarotti, G.L.; Scandolo, S.; Tosatti, E. Decomposition and polymerization of solid carbon monoxide under pressure. Phys. Rev. Lett. 1998, 81, 2092. [CrossRef]

84. Wen, X.-D.; Hoffmann, R.; Ashcroft, N.W. Benzene under high pressure: A story of molecular crystals transforming to saturated networks, with a possible intermediate metallic phase. J. Am. Chem. Soc. 2011, 133, 9023-9035. [CrossRef]

85. Scelta, D.; Ceppatelli, M.; Bini, R. Pressure induced polymerization of fluid ethylene. J. Chem. Phys. 2016, 145, 164504. [CrossRef]

86. Chelazzi, D.; Ceppatelli, M.; Santoro, M.; Bini, R.; Schettino, V. Pressure-induced polymerization in solid ethylene. J. Phys. Chem. B 2005, 109, 21658-21663. [CrossRef]

87. Chelazzi, D.; Ceppatelli, M.; Santoro, M.; Bini, R.; Schettino, V. High-pressure synthesis of crystalline polyethylene using optical catalysis. Nature Mater. 2004, 3, 470. [CrossRef]

88. Citroni, M.; Ceppatelli, M.; Bini, R.; Schettino, V. The high-pressure chemistry of butadiene crystal. J. Chem. Phys. 2003, 118, 1815. [CrossRef]

89. Shirakawa, H.; Ito, T.; Ikeda, S. Raman scattering and electronic spectra of poly(acetylene). Polym. J. 1973, 4, 460-462. [CrossRef]

90. Sakashita, M.; Yamawaki, H.; Aoki, K. FT-IR study of the solid state polymerization of acetylene under pressure. J. Phys. Chem. 1996, 100, 9943-9947. [CrossRef]

91. Ceppatelli, M.; Santoro, M.; Bini, R.; Schettino, V. Fourier transform infrared study of the pressure and laser induced polymerization of solid acetylene. J. Chem. Phys. 2000, 113, 5991-6000. [CrossRef]

92. Trout, C.C.; Badding, J.V. Solid state polymerization of acetylene at high pressure and low temperature. J. Phys. Chem. A 2000, 104, 8142-8145. [CrossRef]

93. Aoki, K.; Kakudate, Y.; Yoshida, M.; Usuba, S.; Tanaka, K.; Fujiwara, S. Solid-state polymerization of acetylene under pressure. Synth. Met. 1989, 28, D91-D98. [CrossRef]

94. Sun, J.; Dong, X.; Wang, Y.; Li, K.; Zheng, H.; Wang, L.; Cody, G.D.; Tulk, C.A.; Molaison, J.J.; Lin, X.; et al. Pressure-induced polymerization of acetylene: Structure-directed stereoselectivity and a possible route to graphane. Angew. Chem. Int. Ed. 2017, 56,1-6. [CrossRef]

95. Ward, M.D.; Huang, H.-T.; Zhu, L.; Biswas, A.; Popov, D.; Badding, J.V.; Strobel, T.A. Chemistry through cocrystals: Pressure-induced polymerization of $\mathrm{C}_{2} \mathrm{H}_{2} \cdot \mathrm{C}_{6} \mathrm{H}_{6}$ to an extended crystalline hydrocarbon. Phys. Chem. Chem. Phys. 2018, 20, 7282-7294. [CrossRef]

96. Ward, M.D.; Huang, H.-T.; Zhu, L.; Popov, D.; Strobel, T.A. High-pressure behavior of $\mathrm{C}_{2} \mathrm{I}_{2}$ and polymerization to a conductive polymer. J. Phys. Chem. C 2019, 123, 11369-11377. [CrossRef]

97. Sharma, S.K.; Rezan, G.S.A.; Misra, V.N.; Tripathi, K.N. Third order nonlinear polymer materials for photonics. J. Mater. Sci. Lett. 2003, 22, 737-738. [CrossRef]

98. Wilhelm, C.; Boyd, S.A.; Chawda, S.; Fowler, F.W.; Goroff, N.S.; Halada, G.P.; Grey, C.P.; Lauher, J.W.; Luo, L.; Martin, C.D.; et al. Pressure-induced polymerization of diiodobutadiyne in assembled cocrystals. J. Am. Chem. Soc. 2008, 130, 4415-4420. [CrossRef]

99. Pruzan, P.; Chervin, J.C.; Thiery, M.M.; Itie, J.P.; Besson, J.M. Transformation of benzene to a polymer after static pressurization to 30 GPa. J. Chem. Phys. 1990, 92, 6910-6915. [CrossRef]

100. Ciabini, L.; Santoro, M.; Bini, R.; Schettino, V. High pressure reactivity of solid benzene probed by infrared spectroscopy. J. Chem. Phys. 2002, 116, 2928. [CrossRef]

101. Cansell, F.; Fabre, D.; Petitet, J.-P. Phase transitions and chemical transformations of benzene up to $550{ }^{\circ} \mathrm{C}$ and 30 GPa. J. Chem. Phys. 1993, 99, 7300-7304. [CrossRef] 
102. Jackson, B.R.; Trout, C.C.; Badding, J.V. UV Raman analysis of the C:H network formed by Compression of benzene. Chem. Mater. 2003, 15, 1820-1824. [CrossRef]

103. Fitzgibbons, T.C.; Guthrie, M.; Xu, E.-S.; Crespi, V.H.; Davidowski, S.K.; Cody, G.D.; Alem, N.; Badding, J.V. Benzene-derived carbon nanothreads. Nat. Mater. 2015, 14, 43-47. [CrossRef] [PubMed]

104. Li, X.; Baldini, M.; Wang, T.; Chen, B.; Xu, E.-S.; Vermilyea, B.; Crespi, V.H.; Hoffmann, R.; Molaison, J.J.; Tulk, C.A.; et al. Mechanochemical synthesis of carbon nanothread single crystals. J. Am. Chem. Soc. 2017, 139, 16343-16349. [CrossRef] [PubMed]

105. Ciabini, L.; Santoro, M.; Gorelli, F.A.; Bini, R.; Schettino, V.; Raugei, S. Triggering dynamics of the high-pressure benzene amorphization. Nat. Mater. 2007, 6, 39-43. [CrossRef] [PubMed]

106. Chen, B.; Hoffmann, R.; Ashcroft, N.W.; Badding, J.; Xu, E.; Crespi, V. Linearly polymerized benzene arrays as intermediates, tracing pathways to carbon nanothreads. J. Am. Chem. Soc. 2015, 137, 14373-14386. [CrossRef] [PubMed]

107. Wang, Y.; Wang, L.; Zheng, H.; Li, K.; Andrzejewski, M.; Hattori, T.; Sano-Furukawa, A.; Katrusiak, A.; Meng, Y.; Liao, F.; et al. Phase transitions and polymerization of $\mathrm{C}_{6} \mathrm{H}_{6}-\mathrm{C}_{6} \mathrm{~F}_{6}$ cocrystal under extreme conditions. J. Phys. Chem. C 2016, 120, 29510-29519. [CrossRef]

108. Wang, Y.; Dong, X.; Tang, X. Pressure-induced Diels-Alder reactions in $\mathrm{C}_{6} \mathrm{H}_{6}-\mathrm{C}_{6} \mathrm{~F}_{6}$ cocrystal towards graphane structure. Angew. Chem. Int. Ed. 2019, 58, 1468-1473. [CrossRef] [PubMed]

109. Nobrega, M.M.; Teixeira-Neto, E.; Cairns, A.B.; Temperini, M.L.A.; Bini, R. One-dimensional diamondoid polyaniline-like nanothreads from compressed crystal aniline. Chem. Sci. 2018, 9, 254-260. [CrossRef] [PubMed]

110. Fanetti, S.; Nobrega, M.M.; Teixeira-Neto, E.; Temperini, M.L.A.; Bini, R. Effect of structural anisotropy in high-pressure reaction of aniline. J. Phys. Chem. C 2018, 122, 29158-29164. [CrossRef]

111. Citroni, M.; Fanetti, S.; Bazzicalupi, C.; Dziubek, K.; Pagliai, M.; Nobrega, M.M.; Mezouar, M.; Bini, R. Structural and electronic competing mechanisms in the formation of amorphous carbon nitride by compressing s-triazine. J. Phys. Chem. C 2015, 119, 28560-28569. [CrossRef]

112. Fanetti, S.; Citroni, M.; Bini, R. Structure and reactivity of pyridine crystal under pressure. J. Phys. Chem. C 2011, 134, 204504. [CrossRef]

113. Yasuzuka, T.; Komatsu, K.; Kagi, H. A revisit to high-pressure transitions of pyridine: A new phase transition at $5 \mathrm{GPa}$ and formation of a crystalline phase over $20 \mathrm{GPa}$. Chem. Lett. 2011, 40, 733-735. [CrossRef]

114. Li, X.; Wang, T.; Duan, P.; Baldini, M.; Huang, H.-T.; Chen, B.; Juhl, S.J.; Koeplinger, D.; Crespi, V.H.; Schmidt-Rohr, K.; et al. Carbon nitride nanothread crystals derived from pyridine. J. Am. Chem. Soc. 2018, 140, 4969-4972. [CrossRef] [PubMed]

115. Ceppatelli, M.; Santoro, M.; Bini, R.; Schettino, V. High pressure reactivity of solid furan probed by infrared and Raman spectroscopy. J. Chem. Phys. 2003, 118, 1499-1506. [CrossRef]

116. Santoro, M.; Ceppatelli, M.; Bini, R.; Schettino, V. High-pressure photochemistry of furane crystal. J. Chem. Phys. 2003, 118, 8321-8325. [CrossRef]

117. Aoki, K.; Baer, B.J.; Cynn, H.C.; Bicol, M. High-pressure Raman study of one-dimensional crystals of the very polar molecule hydrogen cyanide. Phys. Rev. B 1990, 42, 4298-4303. [CrossRef] [PubMed]

118. Völker, T. Polymere Blausäure. Angew. Chem. 1960, 72, 379-384. [CrossRef]

119. Zheng, H.; Li, K.; Cody, G.D.; Tulk, C.A.; Dong, X.; Gao, G.; Molaison, J.J.; Liu, Z.; Feygenson, M.; Yang, W.; et al. Polymerization of acetonitrile via a hydrogen transfer reaction from $\mathrm{CH}_{3}$ to $\mathrm{CN}$ under extreme conditions. Angew. Chem. Int. Ed. 2016, 55, 12040-12044. [CrossRef]

120. Yoo, C.-S.; Nicol, M. Chemical and phase transformations of cyanogen at high pressures. J. Phys. Chem. 1986, 90, 6726-6731. [CrossRef]

121. Yamawaki, H.; Sakashita, M.; Aoki, K. Reversible phase transition between the metastable phases of tetracyanoethylene under high pressure. Phys. Rev. B 1996, 53, 11403-11407. [CrossRef]

122. Gou, H.; Yonke, B.L.; Epshteyn, A.; Kim, D.Y.; Smith, J.S.; Strobel, T.A. Pressure-induced polymerization of $\mathrm{P}(\mathrm{CN})_{3}$. J. Chem. Phys. 2015, 142, 194503. [CrossRef] 
123. Keefer, D.W.; Gou, H.; Wang, Q.; Purdy, A.; Epshteyn, A.; Juhl, S.J.; Cody, G.D.; Badding, J.; Strobel, T.A. Tetracyanomethane under pressure: Extended $\mathrm{CN}$ polymers from precursors with built-in $\mathrm{sp}^{3}$ centers. J. Phys. Chem. A 2018, 122, 2858-2863. [CrossRef] [PubMed]

124. Gou, H.; Zhu, L.; Huang, H.-T.; Biswas, A.; Keefer, D.W.; Chaloux, B.L.; Prescher, C.; Yang, L.; Kim, D.Y.; Ward, M.D.; et al. From linear molecular chains to extended polycyclic networks: Polymerization of dicyanoacetylene. Chem. Mater. 2017, 29, 6706-6718. [CrossRef]

(c)

(C) 2019 by the authors. Licensee MDPI, Basel, Switzerland. This article is an open access article distributed under the terms and conditions of the Creative Commons Attribution (CC BY) license (http://creativecommons.org/licenses/by/4.0/). 